\title{
IncRNA DIGIT and BRD3 protein form phase-separated condensates to regulate endoderm differentiation
}

\author{
Kaveh Daneshvar ${ }^{1,2}$, M. Behfar Ardehali ${ }^{3,4}$, Isaac A. Klein ${ }^{5,6}$, Arcadia J. Kratkiewicz ${ }^{1,2}$, \\ Chan Zhou ${ }^{1,2}$, Amin Mahpour ${ }^{1,2}$, Brett M. Cook ${ }^{7}$, Wenyang Li ${ }^{1,2}$, Joshua V. Pondick ${ }^{1,2}$, \\ Sean P. Moran ${ }^{1,2}$, Richard A. Young ${ }^{5,8}$, Robert E. Kingston ${ }^{3,4}$, Alan C. Mullen ${ }^{1,2,9 \dagger}$ \\ ${ }^{1}$ Gastrointestinal Unit, Massachusetts General Hospital, Boston, MA 02114, USA. \\ ${ }^{2}$ Harvard Medical School, Boston, MA 02115, USA. \\ ${ }^{3}$ Department of Molecular Biology and MGH Research Institute, Massachusetts General Hospital, \\ Boston, MA 02114, USA. \\ ${ }^{4}$ Department of Genetics, Harvard Medical School, Boston, MA 02115, USA. \\ ${ }^{5}$ Whitehead Institute for Biomedical Research, Cambridge, MA 02142, USA. \\ ${ }^{6}$ Department of Medical Oncology, Dana-Farber Cancer Institute, Harvard Medical School, Boston, \\ MA 02215, USA. \\ ${ }^{7}$ Optical Biosystems, Inc. Santa Clara, CA 95050, USA. \\ ${ }^{8}$ Department of Biology, Massachusetts Institute of Technology, Cambridge, MA 02139, USA. \\ ${ }^{9}$ Harvard Stem Cell Institute, Cambridge, MA 02138, USA. \\ ${ }^{\dagger}$ Corresponding author. Thier 306B, 55 Fruit Street, Massachusetts General Hospital, Boston, MA \\ 02114, USA. (617) 726-6342. Email: acmullen@mgh.harvard.edu
}

\begin{abstract}
Gene programs that control differentiation are regulated through the interplay between DNA, RNA, and protein. Cooperation among these fundamental cellular components can occur through highly structured interactions connecting domains formed by specific sequences of nucleotides, ribonucleotides, and/or amino acids and also through the assembly of biomolecular condensates. Here, we show that endoderm differentiation is regulated through the interaction of the long noncoding (Inc) RNA DIGIT and the bromodomain and extra-terminal (BET) domain family protein BRD3. BRD3 forms phase-separated condensates that contain DIGIT, occupies enhancers of endoderm transcription factors, and is required for endoderm differentiation. Purified BRD3 binds to acetylated histone $\mathrm{H} 3$ lysine 18 (H3K18ac) in vitro and occupies regions of the genome enriched in H3K18ac during endoderm differentiation, including the key transcription factors that regulate endoderm differentiation. DIGIT is also enriched in regions of $\mathrm{H} 3 \mathrm{~K} 18 \mathrm{ac}$, and depletion of DIGIT results in decreased recruitment of BRD3 to these regions. Our findings support a model where cooperation between DIGIT and $\mathrm{BRD} 3$ at regions of $\mathrm{H} 3 \mathrm{~K} 18 \mathrm{ac}$ regulates the transcription factors that drive endoderm differentiation and suggest a broader role for protein-IncRNA phase-separated condensates as regulators of transcription in development.
\end{abstract}




\section{Introduction}

Gene expression programs that determine cell identity are regulated by specific interactions between DNA, RNA, and protein, and these expression programs change during differentiation as new interactions are created and previous interactions fall apart. Signaling pathways frequently initiate differentiation (Basson, 2012), and activin or Nodal signaling provide the primary stimulus to direct human embryonic stem cells (hESCs) to differentiate into definitive endoderm (D'Amour et al., 2005; Kubo et al., 2004). Downstream of signaling pathways, differentiation is regulated genetically and epigenetically by coding and noncoding elements of the genome (Gifford et al., 2013). Long noncoding RNAs (IncRNAs) are components of the regulatory circuits that control pluripotency and differentiation into each germ layer (Flynn and Chang, 2014), and the IncRNAs DIGIT, DEANR1, and EVX1 promote mesendoderm and/or definitive endoderm differentiation (Bell et al., 2016; Daneshvar et al., 2016; Jiang et al., 2015; Luo et al., 2016).

DIGIT is an IncRNA that regulates differentiation of human and murine ESCs into definitive endoderm (Daneshvar et al., 2016). DIGIT controls endoderm differentiation, at least in part, through regulation of the transcription factor Goosecoid (GSC). DIGIT is divergently transcribed from the gene encoding GSC, but DIGIT does not need to be expressed in close proximity to GSC in the genome to regulate GSC expression. The mechanism by which DIGIT regulates GSC and controls endoderm differentiation is unknown. Therefore, we employed an RNA-centric approach to define the protein interactome of DIGIT and found that BRD3, a member of the bromodomain and extraterminal (BET) domain family of proteins, showed the strongest interaction.

The BET family of proteins is composed of BRD2, BRD3, BRD4, and testis-specific BRDT (Paillisson et al., 2007). BET proteins contain two bromodomain motifs, which bind acetylated histones (Filippakopoulos et al., 2012; Kanno et al., 2004) and an extraterminal domain that enables them to interact with other proteins including transcription factors, transcription co-activators, pause release factors, and Mediator proteins (Deeney et al., 2016; Jang et al., 2005; Paillisson et al., 2007; Wai et al., 2018). BRD4 has also been the focus of many studies due to its role as a regulator of MYC in cancer (Delmore et al., 2011; Zuber et al., 2011).

BRD2, BRD3, and BRD4 are ubiquitously expressed, but unique functions have been attributed to specific family members in development. Loss of either BRD4 or BRD2 leads to embryonic lethality, but death occurs at different stages, with $\mathrm{Brd} 4^{-/-}$embryos dying before implantation (Houzelstein et al., 2002) and $B r d 2^{--}$embryos dying at midgestation between E9.5 and E11.5 (Shang et al., 2009). BRD4, but not BRD2 or BRD3, also regulates pluripotency and self-renewal of murine ESCs (Di Micco et al., 2014), while BRD2 promotes expression of Nodal when ESCs are released from pluripotency (Fernandez-Alonso et al., 2017). The different activities of BET family proteins in ESCs 
are associated with different patterns of genome occupancy, where BRD4 is enriched primarily at enhancers, and BRD2 and BRD3 are enriched at promoters (Engelen et al., 2015). Furthermore, BRD4 has been shown to form phase-separated droplets in murine ESCs, which have been proposed to promote recruitment of transcription machinery to regulate gene expression (Sabari et al., 2018). While critical roles for BRD2 and BRD4 have been established in early development, the function of BRD3 is not well understood.

Here we report that DIGIT interacts with BRD3 and is found with BRD3 in phaseseparated condensates during endoderm differentiation. With differentiation, BRD3 occupies new sites at endoderm genes, many of which are also regulated by DIGIT. Recombinant BRD3 preferentially recognizes histone $\mathrm{H} 3$ lysine 18 acetylation (H3K18ac), a modification produced by the transcription co-activators CBP/p300 (Jin et al., 2011), and BRD3 co-occupies the genome with H3K18ac. DIGIT is also enriched at sites of H3K18ac, and depletion of DIGIT reduces BRD3 occupancy at these sites. We propose that BRD3 is recruited to sites of H3K18ac to form phase-separated condensates and promote transcription, and this recruitment of BRD3 is dependent on DIGIT. Thus, the interaction between DIGIT and BRD3 at sites of H3K18ac leads to activation of genes that regulate endoderm differentiation.

\section{Results}

\section{Design of an aptamer-based approach to define the DIGIT-protein interactome}

DIGIT transcripts are retained in the nucleus and regulate genes that control endoderm differentiation (Daneshvar et al., 2016). We asked whether DIGIT transcripts directly interact with nuclear proteins in hESCs undergoing endoderm differentiation. We fused the 3' end of the cDNA encoding DIGIT to four copies of an aptamer with high affinity for streptavidin (4xS1m) (Leppek and Stoecklin, 2014; Srisawat and Engelke, 2001). We performed single-molecule RNA-FISH (smFISH) in hESCs after transient transfection with a plasmid expressing DIGIT-4xS1m and differentiated hESCs toward definitive endoderm. Under these conditions, the DIGIT-4xS1m chimeric RNA molecules are retained in the nucleus (Figure 1A), as previously described for endogenous DIGIT.

We next asked if DIGIT-4xS1m chimeric transcripts were precipitated with streptavidin beads in UV cross-linked cells (Figure 1B). We tested DIGIT enrichment with increasing concentrations of potassium chloride $(\mathrm{KCl})$ in the wash buffer and determined that at $350 \mathrm{mM} \mathrm{KCl}$ DIGIT enrichment is well above GAPDH (Figure S1A). qRT-PCR showed 125-fold enrichment of DIGIT-4xS1m compared to GAPDH mRNA after streptavidin precipitation (Figure 1C). Together, these experiments show that the $4 \times S 1 \mathrm{~m}$ aptamer can be fused to IncRNAs and used to enrichm of IncRNAs in UV cross-linked cells. 
A

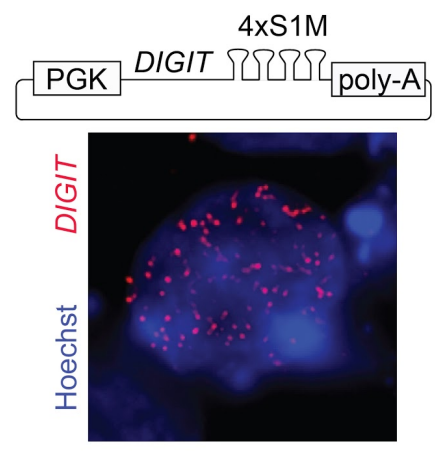

B

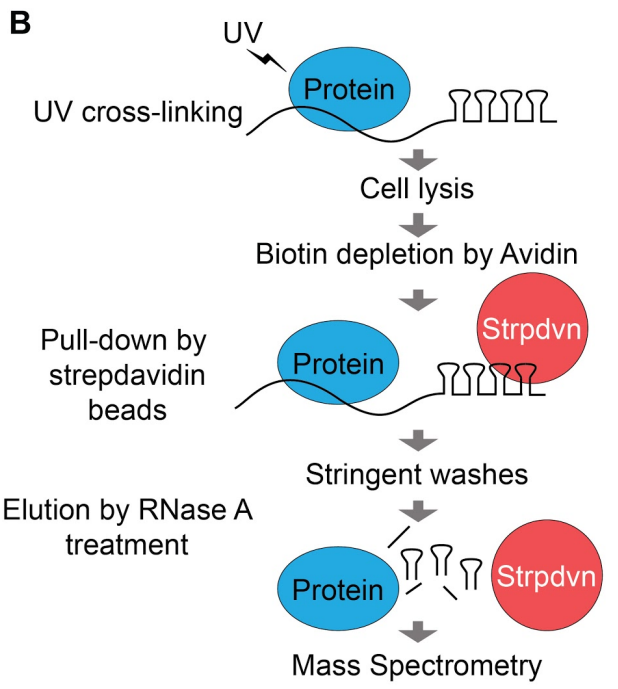

C

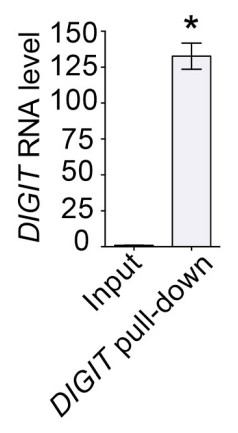

D

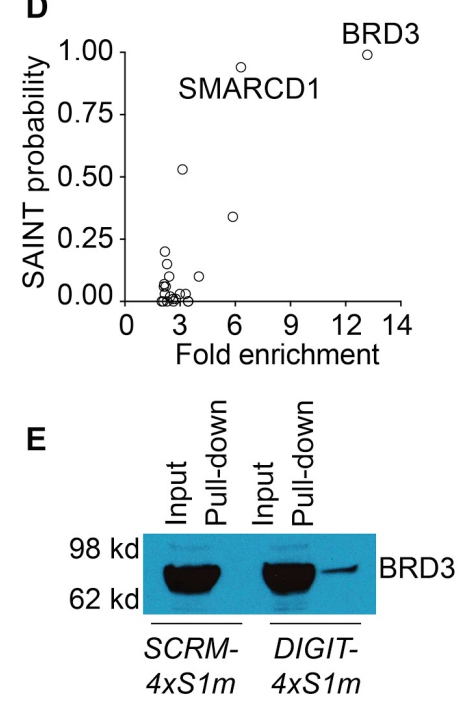

$\mathbf{F}$
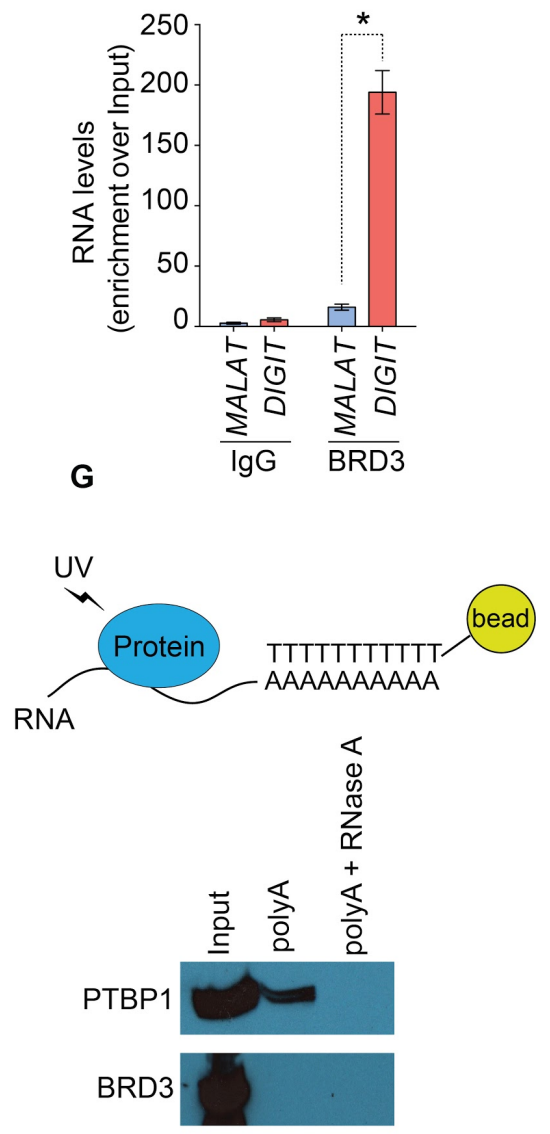

Figure 1. DIGIT interacts with BRD3 in definitive endoderm cells.

(A) Schematic map of the construct expressing DIGIT fused to four S1m aptamers (DIGIT-4xS1m, top). RNA-FISH was performed to detect ectopically expressed DIGIT-4xS1m chimeric RNA in hESCs (bottom). DIGIT transcripts are red and the nucleus is shown in blue (Hoechst). (B) Strategy for UV crosslinking, streptavidin-assisted pull-down of ectopically-expressed DIGIT, and mass spectrometry analysis of interacting proteins in endoderm cells. (C) qRT-PCR was performed to quantify enrichment of DIGIT$4 x S 1 m$ (left) and scrambled DIGIT (SCRM-4xS1m) (right) after streptavidin pull-down. * indicates $p$ $<0.0001$. (D) Proteomic analysis of the mass spectrometry data for DIGIT-4xS1m compared to SCRM$4 \times S 1 m$ and to DIGIT without aptamers on day 4 of endoderm differentiation. The x-axis indicates fold enrichment compared to controls. The y-axis indicates the probability score for each interaction based on the SAINT (Significance Analysis of INTeractome) score. (E) Immunoblot for BRD3 was performed using cell lysates on day 4 of endoderm differentiation ( $5 \%$ input) and then after streptavidin-assisted pull-down of SCRM-4xS1m and DIGIT-4xS1m. (F) RNA-Immunoprecipitation (RIP) was performed on day 4 of endoderm differentiation using an anti-BRD3 antibody or an IgG isotype control. qRT-PCR was performed to quantify expression of DIGIT. Enrichment of IncRNA MALAT1 is shown as a negative control. * indicates $p<0.0001$. (G) hESCs were differentiated for 4 days before UV cross-linking and pull-down of polyadenylated (polyA) RNAs. The immunoblot was performed to detect protein levels of PTBP1 (top) and BRD3 (bottom). PolyA selection after RNase A treatment was performed to confirm that enrichment was due to interaction with polyA RNA. 


\section{DIGIT interacts with BRD3}

To identify the proteins that interact with DIGIT transcripts in differentiating cells, we transiently expressed DIGIT-4xS1m transcripts in hESCs that were differentiating toward endoderm. As a control, we ectopically expressed a scrambled form of DIGIT fused to $4 \times \mathrm{S} 1 \mathrm{~m}$ (SCRM-4xS1m) and the DIGIT transcript without the 4xS1m aptamers. We performed UV cross-linking followed by streptavidin precipitation in cells expressing each transcript. Proteins released by RNase $A$ digestion were resolved on a polyacrylamide gel prior to analysis by mass spectrometry (MS). After obtaining the spectral counts for each sample, we used a proteomics analysis pipeline to identify candidate proteins that interact with DIGIT (Mellacheruvu et al., 2013) (Crapome.org). We set a threshold of $>90 \%$ confidence and greater than four-fold enrichment over controls. This analysis identified BRD3 as the protein with the highest interaction score (Figure 1D and 1E, Table S1). The other protein to pass this threshold was SMARCD1, a component of the SWI/SNF chromatin remodeling complex (Oh et al., 2008) which is involved in embryonic stem cell differentiation (Alajem et al., 2015).

Since aptamer experiments were performed using ectopically expressed DIGIT transcripts that localized to the nucleus, it is possible that differences in the number of DIGIT molecules present in a cell during endoderm differentiation could lead to interactions that are not formed with endogenous DIGIT. To validate the interaction of BRD3 with endogenous DIGIT during endoderm differentiation, we performed RNAimmunoprecipitation (RIP) in nuclear lysates of differentiating cells using an antibody against BRD3 and quantified enrichment of the DIGIT transcript (Figure 1F). RNA precipitated with BRD3 demonstrated a 175-fold increase in DIGIT compared to RNA precipitated with IgG. This enrichment was observed at a much lower level for MALAT1, an abundant nuclear IncRNA. These results suggest that BRD3 interacts with DIGIT during endoderm differentiation.

BRD3 does not broadly associate with RNA and shows specificity for DIGIT compared to BRD2 and BRD4

BRD2, BRD3, and BRD4 have been shown to interact with a small number of RNAs transcribed from enhancer regions (eRNAs) (Rahnamoun et al., 2018). However, the specificity of the interactions and whether these proteins bind to other RNA species are not known. DIGIT transcripts are polyadenylated (polyA) (Sigova et al., 2013), and we asked if BRD3 associates broadly with polyA RNAs. We UV cross-linked hESCs and precipitated polyA RNAs from nuclear extracts using oligo-dT-coated beads (Castello et al., 2016). As a positive control, we performed an immunoblot for Polypyrimidine Tract Binding Protein 1 (PTBP1), a protein that is associated with RNA splicing (GarciaBlanco et al., 1989) and has been shown to interact with IncRNAs (Lin et al., 2014; Ramos et al., 2015) (Figure 1G). Despite enrichment of PTBP1 with polyA RNA precipitation, BRD3 was not detected in association with polyA RNAs. Beta-ACTIN 
served as a negative control for this experiment, as we did not find evidence in the literature of RNA-binding activity for this protein. Treatment with RNase A also confirmed that the interaction detected between PTBP1 and polyA RNAs was dependent on the presence of RNAs. These results suggest that BRD3 interacts with DIGIT, but BRD3 does not broadly interact with polyA RNAs.

BRD2, BRD3, and BRD4 but not BRDT are expressed upon endoderm differentiation (Figure S1B), and we asked if the other BET family proteins present during differentiation also interact with DIGIT. We performed RIP to quantify the interaction between DIGIT and BRD2, BRD3, and BRD4 during endoderm differentiation. Consistent with our previous analyses, we observed enrichment of DIGIT with precipitation of BRD3. However, enrichment of DIGIT was significantly reduced with precipitation of BRD2 and BRD4 compared to BRD3 (Figure S1C). These findings reveal that BRD3 exhibits specificity in its interactions with RNA, and BRD3 has a higher affinity for DIGIT than either BRD2 or BRD4.

\section{DIGIT localizes within large BRD3 puncta}

To further investigate the interactions between DIGIT and BRD3, we visualized DIGIT and BRD3 within the nuclei of differentiating cells. We observed that $18 \%$ of DIGIT transcripts overlap with BRD3 staining (Figure 2A and 2B). This overlap was significantly higher than the overlap observed between BRD3 protein and GSC mRNA $(<1 \%)$ (Figure 2B, left). DIGIT is primarily retained in the nucleus while the majority of GSC mRNA is in the cytoplasm (Daneshvar et al., 2016). For this analysis, we focused only on transcripts localized to the nucleus for both DIGIT (379) and GSC mRNA (2412). The higher number of GSC transcripts reflects the larger number of GSC mRNA molecules in cells at day 4 of endoderm differentiation. The images also revealed that BRD3 is not evenly distributed through the nucleus. Instead, BRD3 tends to form puncta, a phenomenon that has been described for BRD4 (Sabari et al., 2018). We observed that, when compared to nuclear GSC mRNA molecules that overlap with BRD3 staining, DIGIT transcripts are more likely to localize in larger BRD3 puncta (Figure 2B, right). The analysis also revealed multiple sites of overlap between BRD3 and DIGIT in nuclei, indicating that we are not simply observing sites of DIGIT transcription inside BRD3 condensates as could be hypothesized if there were only 1-2 sites of overlap in each cell. These results suggest that DIGIT transcripts frequently associate with BRD3 puncta during endoderm differentiation.

\section{BRD3 shows properties of liquid-liquid phase-separated condensates}

Disordered proteins can form biological condensates and interact with RNA (Castello et al., 2016; He et al., 2016). Analysis of the primary sequence of BRD3 using PONDR VSL2 showed that $75 \%$ of the long isoform of BRD3 and $67 \%$ of the short isoform of BRD3 are disordered (Figure S2A). To further investigate the possibility that BRD3 
puncta are phase-separated condensates, we first asked if BRD3, expressed as a fusion protein with EGFP, forms condensates in live cells. We used the CRISPR/Cas system to insert a monomeric EGFP (mEGFP) gene into the 5' end of the endogenous $B R D 3$ gene (Figure $\mathrm{S} 2 \mathrm{~B}$ and $\mathrm{S} 2 \mathrm{C}$ ). The generation of fused mEGFP-BRD3 was confirmed by immunoblot after pull-down with an antibody recognizing GFP (Figure S2D). Confocal microscopy of differentiating cells confirmed the formation of BRD3 puncta in both live and fixed endoderm cells (Figure 2C). As a control, we generated hESCs that stably express mEGFP fused to a nuclear localization signal (NLS). Live imaging and immunostaining of GFP in these mEGFP-expressing cells show that mEGFP by itself is not capable of forming puncta in differentiating cells.

Phase-separated condensates have a liquid-like state and can exchange with their surroundings (Boija et al., 2018; Lu et al., 2018; Sabari et al., 2018). To test whether BRD3 puncta display rapid exchange kinetics with their surroundings, we performed Fluorescence Recovery After Photobleaching (FRAP) analysis of EGFP-tagged BRD3 proteins in live endoderm cells. After photobleaching, the BRD3 puncta are able to recover up to $20 \%$ in 10 seconds and up to $38 \%$ in 30 seconds (Figure 2D and 2E). These results showed that BRD3 molecules can form puncta with properties consistent with liquid-liquid phase-separated condensates, and that components of these condensates can dynamically exchange molecules with their surroundings.

The evidence from imaging suggests that BRD3 forms phase-separated condensates in hESCs and with endoderm differentiation (Figure 2C, 2D, and S2E). BRD4 forms condensates in hESCs (Sabari et al. 2018), and BRD2, BRD3, and BRD4 all have large domains of predicted disorder (Figure S2A). We found that all three proteins form puncta with endoderm differentiation and that BRD3 forms puncta that are separate from BRD4 and BRD2 (Figure 2F). Overall, these findings suggest that each BET family protein form distinct puncta with endoderm differentiation. 
A
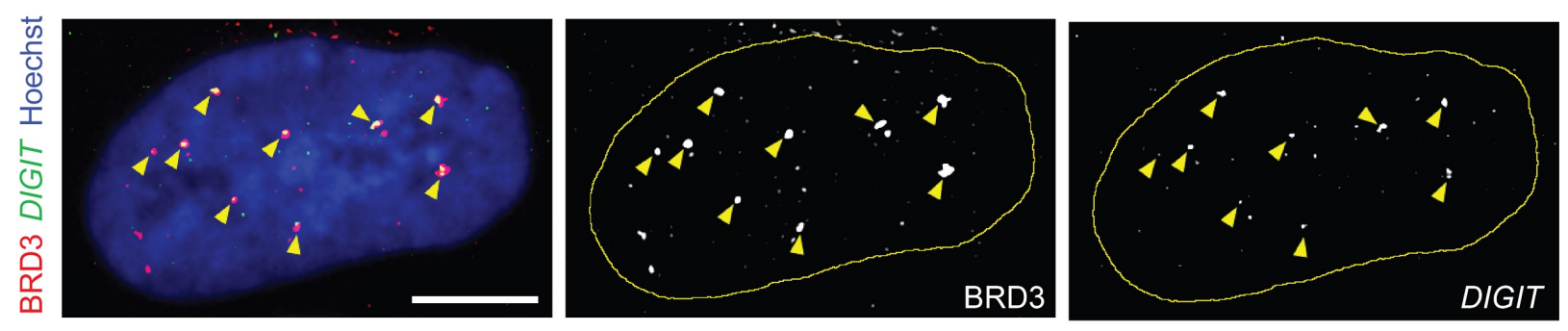

B

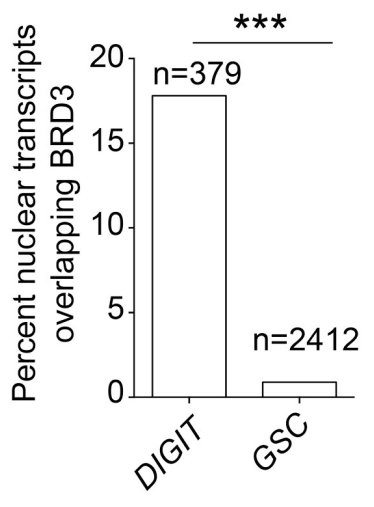

D

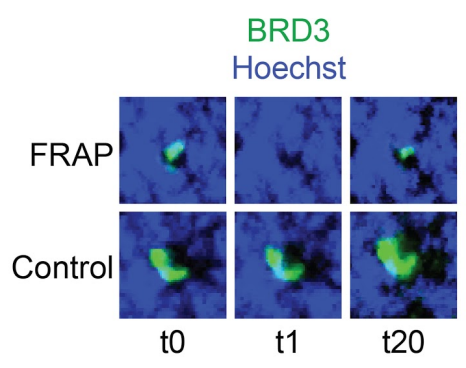

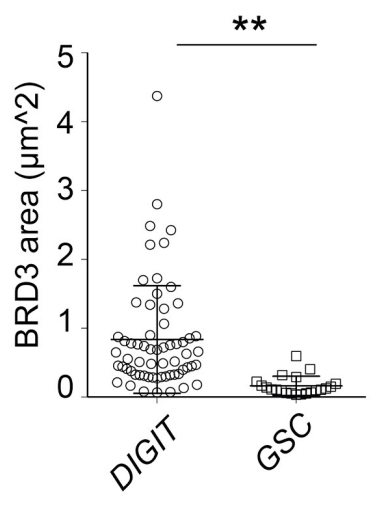

E

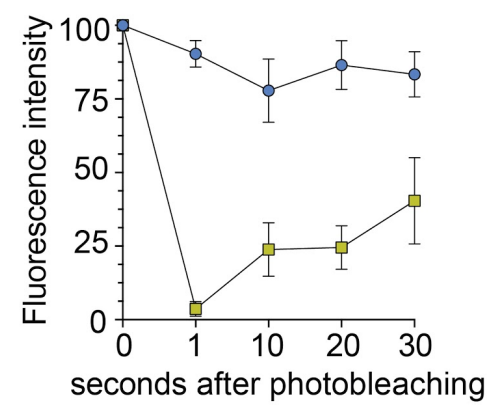

C BRD3-mEGFP
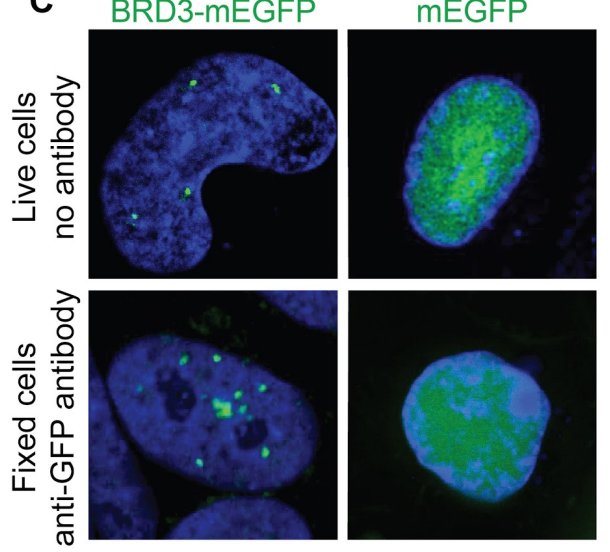

F

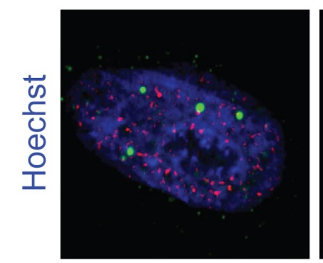

mEGFP-BRD3 BRD4

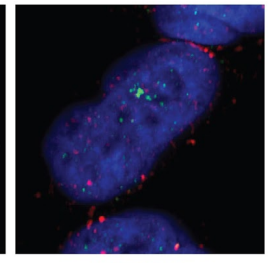

BRD3

BRD2

Figure 2. BRD3 forms protein-RNA phase-separated condensates.

(A) Sequential immunofluorescence and RNA-FISH shows the distribution of BRD3 protein (red) and DIGIT RNA (green) within the nucleus (blue) on day 4 of endoderm differentiation (first panel). Areas of overlap are shown in yellow and marked with yellow arrows. The second panel shows BRD3 protein (white) and the third panel shows DIGIT RNA (white) for the same cell. The nuclei are outlined in yellow for the second and third panel. Scale bar represents $10 \mu \mathrm{m}$. (B) The bar chart shows the number of DIGIT IncRNA and GSC mRNA molecules inside the BRD3 staining area (left). ${ }^{* * *}$ indicates $p<0.0001$ (Fisher exact test). The plot on the right shows the distribution of DIGIT and GSC transcripts that overlap with BRD3, as a function of BRD3 condensate size. ${ }^{* *}$ indicates $p<0.001$. (C) Live (top) and fixed cell (bottom) fluorescence images of BRD3 condensates (green) are shown in nuclei (blue). (D) FRAP analysis of BRD3 condensates (green) before photobleaching (t0) and 1 second (t1) and 20 seconds (t20) after photobleaching. (E) Quantification of the FRAP experiment imaged in (D). (F) Co-immunostaining of BRD3 (green) with BRD4 (red, left) or BRD2 (red, right) in endoderm cells. 


\section{Formation of BRD 3 condensates is concentration-dependent and can enrich RNA}

The proteins that compose phase-separated biomolecular condensates may form liquid droplets in vitro (Banani et al., 2017). To test the protein concentration dependency of phase-separated BRD3 condensates, we produced recombinant BRD3 fused to mEGFP and purified this protein from eukaryotic cells (Figure S3A). A titration of the protein showed that BRD3 can form droplets at concentrations as low as $5 \mu \mathrm{M}$ (Figure 3A). Phase-separated droplets which rely on electrostatic interactions are sensitive to salt, so we asked if recombinant BRD3 can form droplets at physiological salt concentrations. A titration of the salt showed that BRD3 can form droplets in salt concentrations as high as $300 \mathrm{mM}$ (Figure 3B). We next asked if BRD3 condensates formed in vitro interact with the DIGIT transcript. We synthesized Cy3-labeled DIGIT (Figure S3B) and induced in vitro formation of BRD3 condensates in the presence of Cy3-DIGIT. We observed that the Cy3-DIGIT molecules were concentrated within BRD3 condensates (Figure 3C), while Cy3-DIGIT molecules alone remain dispersed (Figure $3 \mathrm{C}$, far right). These results show that BRD3 forms phase-separated condensates that recruit DIGIT in vitro. Although these results do not provide concrete evidence that BRD3 condensates have specific affinity for the DIGIT transcript, they support a model where BRD3 condensates form a suitable environment for interaction with RNAs. Additional studies will be needed to address the selectivity of BRD3 condensates for specific RNA species. 
A

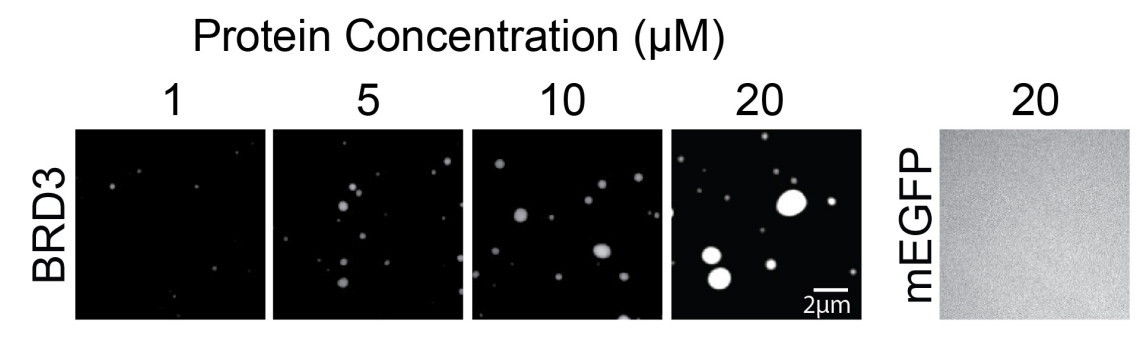

B

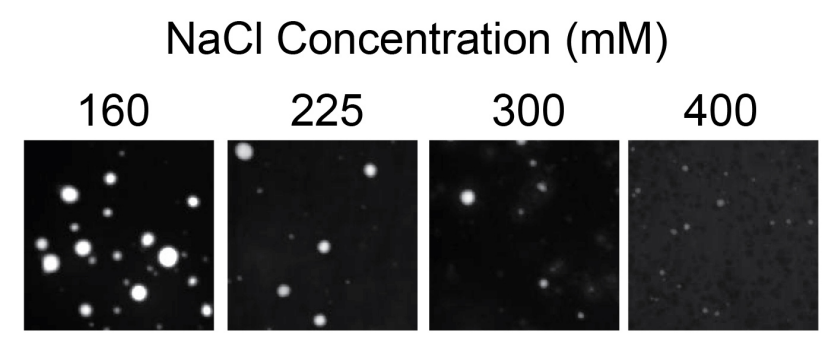

C
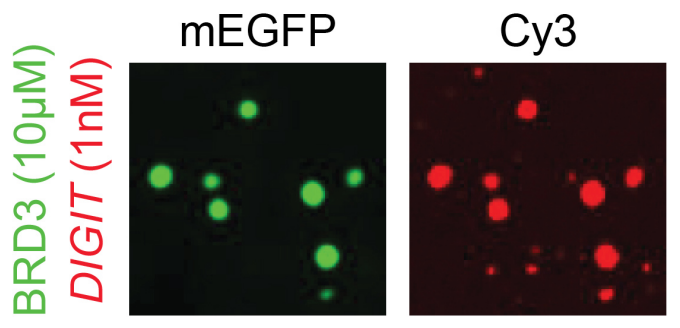

Merge
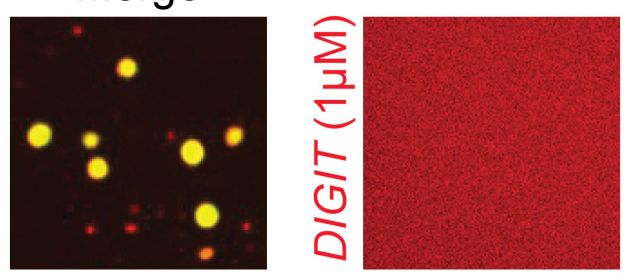

Figure 3. BRD3 protein forms phase-separated condensates in vitro.

(A) Purified recombinant BRD3 fused to monomeric (m) EGFP forms phase-separated condensates, indicated by white circles on a black background, at the indicated concentrations. Purified recombinant mEGFP is used as control (far right). (B) In vitro formation of BRD3 condensates as a function of salt concentration. $10 \mu \mathrm{M}$ BRD3-mEGFP was incubated at the indicated salt concentrations and assessed for droplet formation. (C) BRD3 condensates can enrich labeled DIGIT. Enrichment of fluorescently labeled DIGIT (Cy3, red) within BRD3-mEGFP droplets (green). The overlap between BRD3-mEGFP and DIGITCy3 is shown in yellow (merge). Cy3-DIGIT alone is shown on the far right $(1 \mu \mathrm{M})$. Concentrations of BRD3 and DIGIT used for mixing are indicated at the far left. 


\section{$B R D 3$ regulates definitive endoderm differentiation}

BRD3 is dispensable for maintenance of ESC pluripotency (Di Micco et al., 2014), but its role in endoderm differentiation is not clear. We used the CRISPR/Cas system to generate homozygous hESCs lines deficient in BRD3 $\left(B R D 3^{-/}\right)$(Figure $4 \mathrm{~A}$ and S4) by inserting a puromycin (puro) resistance cassette followed by a stop codon after the first amino acid of BRD3. As a negative control, we used the CRISPR/Cas system to insert a puro resistance cassette into the AAVS1 locus. qRT-PCR analysis showed that mRNA levels of OCT4 and NANOG are comparable between BRD $3^{-/-} \mathrm{hESCs}$ and control cells (Figure 4B), suggesting that pluripotency was not affected by the loss of BRD3.

We next differentiated $B R D 3^{-/}$hESCs toward definitive endoderm. qRT-PCR showed that mRNA levels of SOX17 and CXCR4, markers of definitive endoderm, are significantly reduced with differentiation of $B R D 3^{-/}$cells compared to controls (Figure 4C). To provide further evidence that the loss of BRD3 inhibited definitive endoderm differentiation, we performed flow cytometry to quantify the production of definitive endoderm by co-expression of CXCR4 and c-KIT. We again observed a decrease in the definitive endoderm population in $B R D 3^{-/}$cells (Figure 4D). For these differentiation experiments (Figure $4 C$ and $4 D$ ), activin treatment was used to direct the differentiation of hESCs into definitive endoderm (D'Amour et al., 2005). We then evaluated the necessity of BRD3 under other differentiation conditions. We cultured $B R D 3^{-/}$and control hESCs on micropatterned slides in the presence of BMP4 to induce differentiation of ectoderm, mesoderm, and endoderm (Deglincerti et al., 2016a; Warmflash et al., 2014). Under these conditions, differentiation is organized spatially, with ectoderm (SOX2) in the central region, definitive endoderm (SOX17) on the periphery, and mesoderm between ectoderm and endoderm. BRD $3^{-/}$cells showed reduced SOX17 expression on the periphery of differentiating colonies as well as an expansion of central cells staining for SOX2 (Figure 4E). These results demonstrate that loss of BRD3 inhibits endoderm differentiation, a phenotype also observed with depletion of DIGIT (Daneshvar et al., 2016). 
A

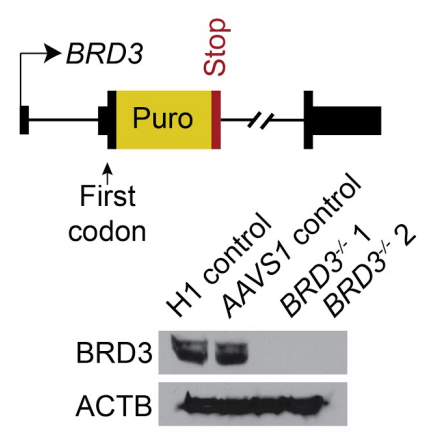

B

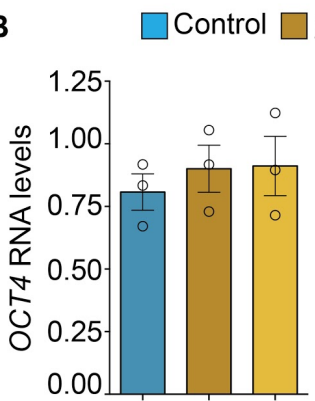

C

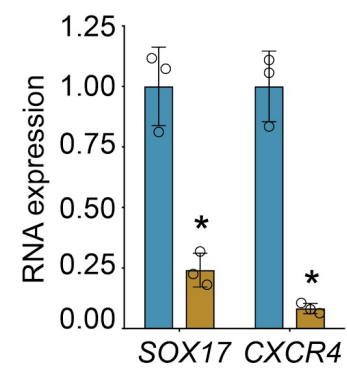

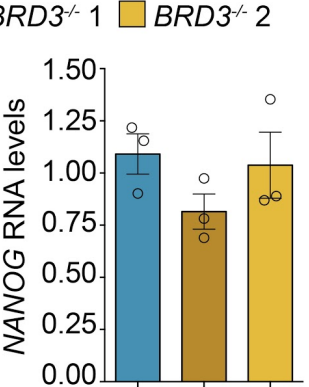

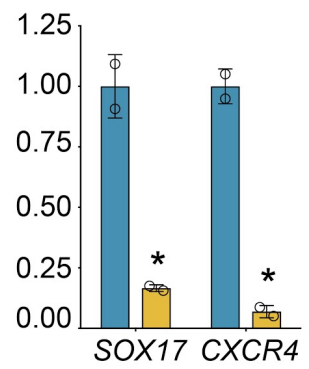

D

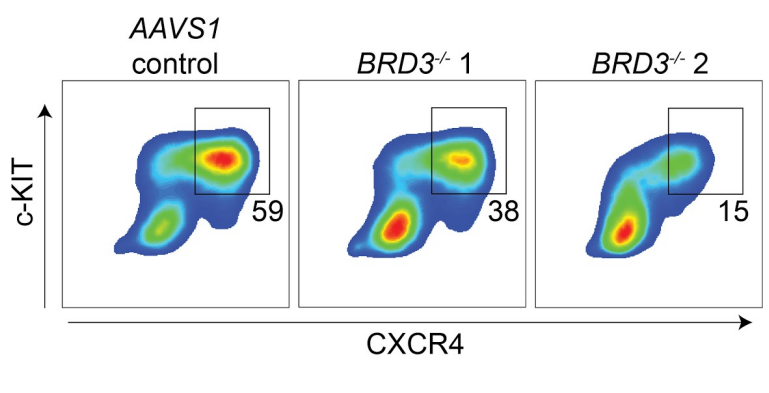

E
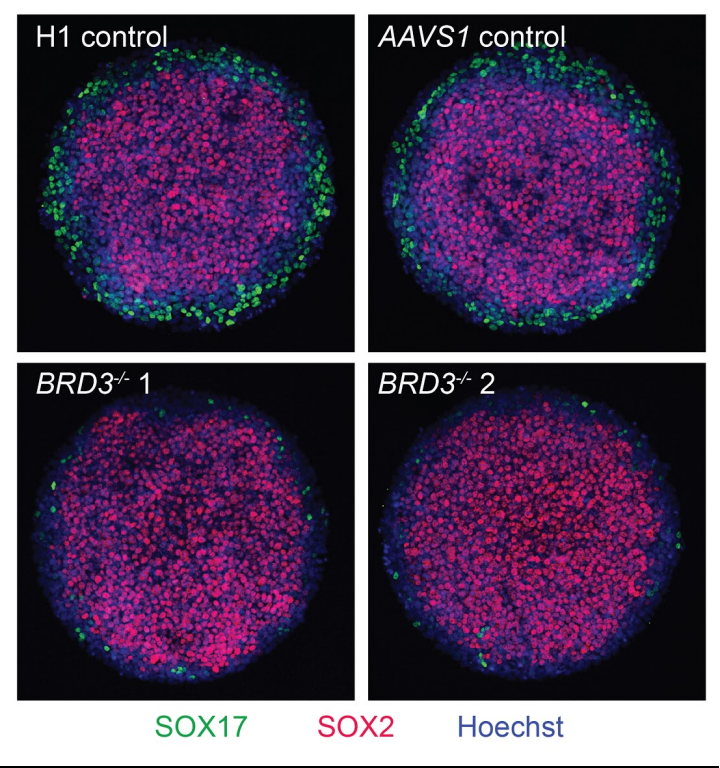

Figure 4. BRD3 regulates endoderm genes.

(A) Strategy for depletion of BRD3 in hESCs using the CRISPR/Cas system and a homology plasmid to insert a puromycin resistance cassette and stop codon into the first exon of $B R D 3$ (top). Immunoblot was performed on cell lysates using an anti-BRD3 antibody. Samples were tested from unmodified H1 hESCs ( $\mathrm{H} 1$ Control), hESCs in which a puromycin cassette was inserted into the AAVS1 locus (AAVS1 Control), and two independently-derived $B R D 3^{-/}$lines (1 and 2). ACTB was used as a loading control. (B) qRTPCR was performed to quantify OCT4 (POU5F1) and NANOG in control hESCs and two independentlyderived $B R D 3^{-/-}$lines. (C) qRT-PCR was performed to quantify SOX17 and CXCR4 using control hESCs and two independently-derived $B R D 3^{-/}$lines. Gene expression was analyzed after 4 days of directed differentiation. * indicates $p<0.05$. (D) Flow cytometry was performed to quantify expression of CXCR4 and C-KIT in AAVS1 control cells and two independently-derived BRD ${ }^{-/}$lines. The analysis was performed after 4 days of directed differentiation. Percentages of definitive endoderm cells are indicated under the boxes. (E) The indicated hESCs were differentiated by treatment with BMP4 for 2 days on micropatterned slides. Immunofluorescent staining was performed for SOX2 (red) and SOX17 (green) and nuclei were counterstained with Hoechst (blue). 


\section{BRD3 interacts with acetylated $H 3 K 18$}

Individual bromodomains of the BRD3 protein have been shown to interact with acetylated histones (Filippakopoulos et al., 2012), but the affinity of full-length BRD3 protein for modified histones has not been investigated. To understand how full-length BRD3 regulates genomic targets, we asked which histone modifications are recognized by BRD3. We hybridized the long and short isoforms of recombinant BRD3 protein to a histone modification peptide array and found that BRD3 shows the strongest interaction with acetylated histone $\mathrm{H} 3$ lysine 18 (H3K18ac) (Figure 5A, 5B, S5A, and S5B). This interaction was not detected with either bromodomain of BRD3 alone (Filippakopoulos et al., 2012).

\section{BRD3 and H3K18ac co-occupy genes that regulate pluripotency and differentiation}

Because BRD3 preferentially binds H3K18ac in vitro, we wanted to determine if this interaction also extends to the native chromatin in live cells. We performed ChIP-seq for BRD3 in hESCs and after 4 days of endoderm differentiation and compared occupancy of BRD3 at the DIGIT/GSC locus (Figure 5C) to acetylation of H3K18 (Dixon et al., 2015). We observed no evidence of BRD3 occupancy or H3K18ac at this locus in hESCs. However, BRD3 occupies this locus in endoderm. Mesendoderm gives rise to endoderm, and many endoderm genes, including GSC, are first activated in mesendoderm (Tada et al., 2005; Vallier et al., 2009). In mesendoderm, we observed H3K18ac in the same regions of the DIGIT/GSC locus that are occupied by BRD3 in endoderm. In contrast, BRD3 occupied regions of H3K18ac in hESCs at the gene encoding the pluripotency factor SOX2, and both BRD3 occupancy and H3K18ac are reduced with endoderm/mesendoderm differentiation (Figure 5D). These findings show that BRD3 and H3K18ac co-occupy genes in hESCs and with differentiation.

\section{DIGIT is enriched in regions of chromatin modified by H3K18ac}

BRD3 localizes to actively transcribed regions of chromatin marked by H3K18ac and it physically interacts with DIGIT, suggesting that DIGIT localizes to actively transcribed regions of chromatin. We adapted the Cleavage Under Targets and Release Using Nuclease (CUT\&RUN) (Skene and Henikoff, 2017) approach to isolate RNA molecules that interact with specific histone modifications (leavage Under Targets and $\underline{R}$ elease Using Nuclease to Assess Enrichment of RNA, CUT\&RUNER) (Figure 5E). The CUT\&RUN protocol uses micrococcal nuclease (MNase) to excise DNA at targeted regions. MNase function is dependent on calcium cations, and it can target both DNA and RNA molecules. However, its RNase activity can be inhibited by addition of heavy metal cations without significantly compromising its DNase activity (Cuatrecasas et al., 1967). We tested two heavy metal cations (barium and strontium), which have been reported to inhibit the RNase activity of MNase. We determined that both barium and strontium cations can inhibit the RNase activity of MNase (Figure S5C and S5D). We 
then used our modified approach to test enrichment of the IncRNA MALAT1, which interacts with chromatin at sites enriched for $\mathrm{H} 3 \mathrm{~K} 4 \mathrm{me} 3$, a marker of active promoters (West et al., 2014). Results of CUT\&RUNER show that MALAT1 transcripts are enriched at regions modified by $\mathrm{H} 3 \mathrm{~K} 4 \mathrm{me} 3$ compared to $\mathrm{H} 3 \mathrm{~K} 18 \mathrm{ac}$ or the repressive mark H3K27me3. We then quantified enrichment of DIGIT in regions with H3K4me3 and H3K18ac. DIGIT demonstrates the greatest enrichment in regions modified by $\mathrm{H} 3 \mathrm{~K} 18 \mathrm{ac}$ (Figure 5F). Enrichment was also observed in regions modified by H3K4me3, but not with IgG control or regions modified by H3K27me3. We do not find enrichment for SOX17 mRNA in any of these regions. These results show that BRD3 and DIGIT are both enriched in regions of chromatin modified by H3K18ac. 
A

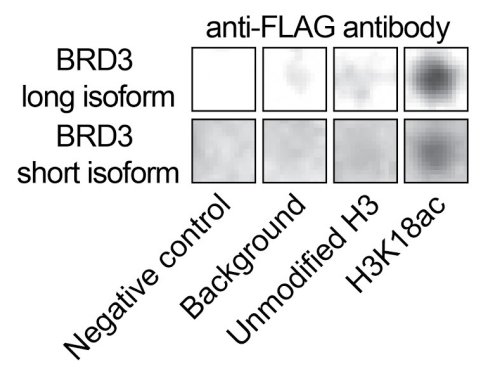

C

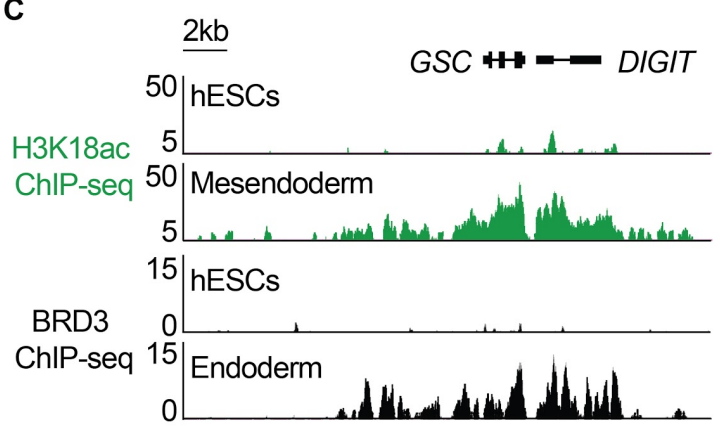

$E$

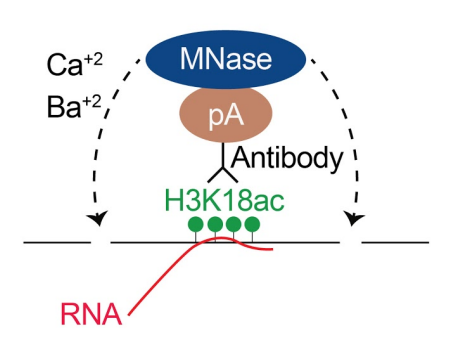

B

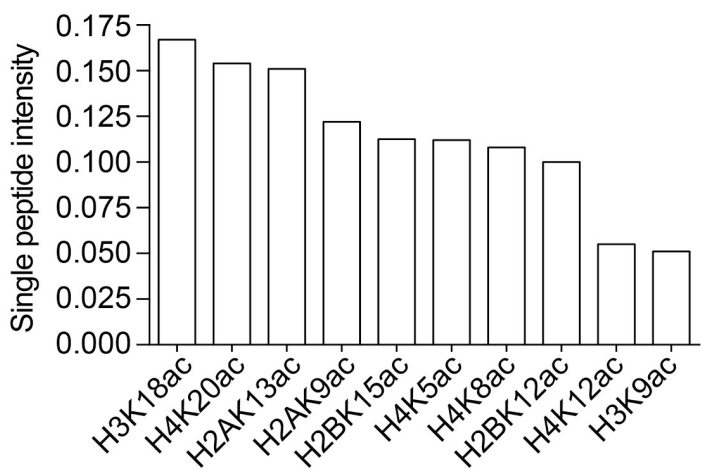

D
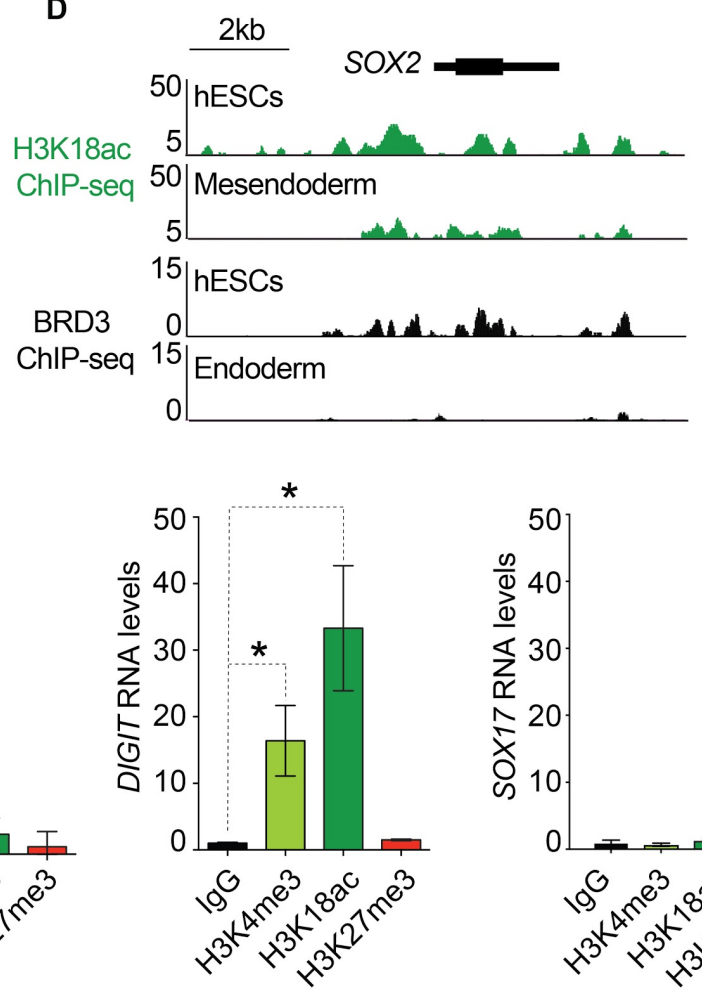

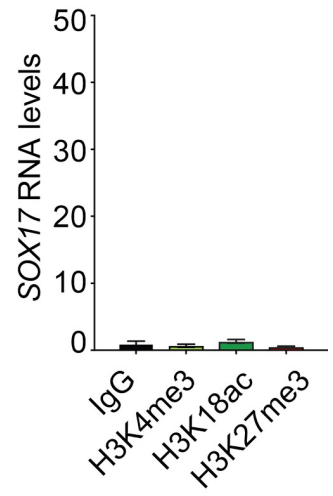

Figure 5. BRD3 and DIGIT interact with acetylated H3K18.

(A) Binding of recombinant BRD3 to H3K18ac on a peptide modification array. Two replicates are shown, and the full arrays are shown in Figure S5A. (B) The top 10 modifications bound by recombinant BRD3 protein (long isoform). (C) and (D) show BRD3 occupancy (black) and H3K18ac (green) in hESCs and in mesendoderm (H3K18ac) and endoderm (BRD3) differentiation at GSC/DIGIT and SOX2, markers of definitive endoderm and pluripotency respectively. Y-axis in the ChIP-seq tracks denote normalized read count. (E) Schematic shows the strategy for CUT\&RUNER, which takes advantage of targeted Protein A (pA) fused MNase digestion of chromatin fragments followed by isolation of the chromatin-bound RNA. (F) qRT-PCR shows the levels of MALAT1 (left), DIGIT (middle), and SOX17 (right) isolated by performing CUT\&RUNER in hESCs differentiated toward definitive endoderm. RNA levels are normalized to $G A P D H$ expression. * indicates $p<0.05$. 


\section{BRD3 promotes gene expression through occupancy of enhancers}

BRD3 primarily occupies promoters in hESCs and shows increased occupancy of enhancers with endoderm differentiation (Figure 6A and S6A). In both cell types, BRD3 occupies genes enriched in DNA binding and transcription activity (Figure 6B). DIGIT is induced with endoderm differentiation and interacts with BRD3, and we investigated the overlap between genes occupied by BRD3 and those regulated by DIGIT. We identified 1337 genes occupied by BRD3 in endoderm differentiation and compared this to the genes inhibited in DIGIT-deficient cells during endoderm differentiation (Daneshvar et al., 2016). Fifty-eight genes were occupied by BRD3 in endoderm differentiation and depleted with the loss of DIGIT, including the key endoderm and mesendoderm genes GSC, FOXA2, and EOMES (Figure $6 \mathrm{C}$ and $6 \mathrm{D}$ ). We also observed that these regulatory genes are located in larger domains occupied by BRD3, and genes in these larger domains are enriched in pathways of embryonic morphogenesis and pattern specification (Figure S6B). These results suggest that upon endoderm differentiation, BRD3 shifts to preferentially occupy enhancers, including those that regulate genes that control endoderm fate. 
A
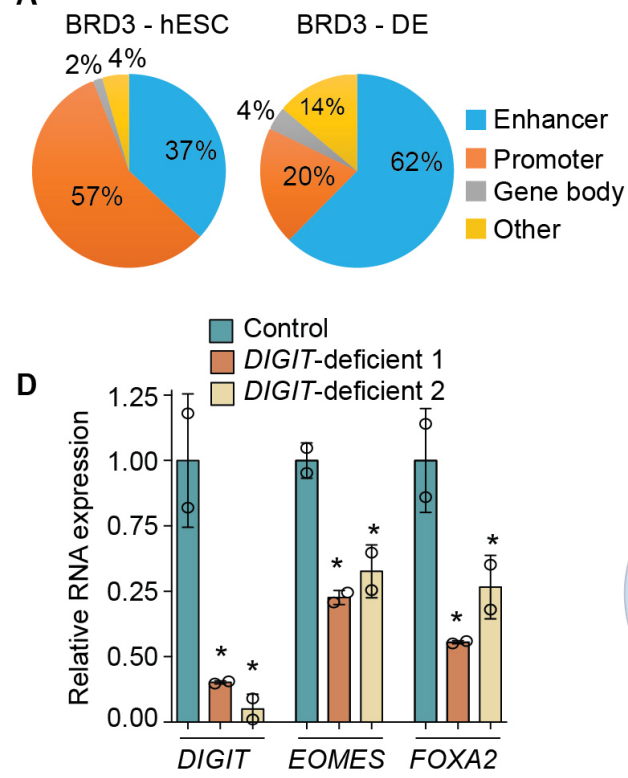

G

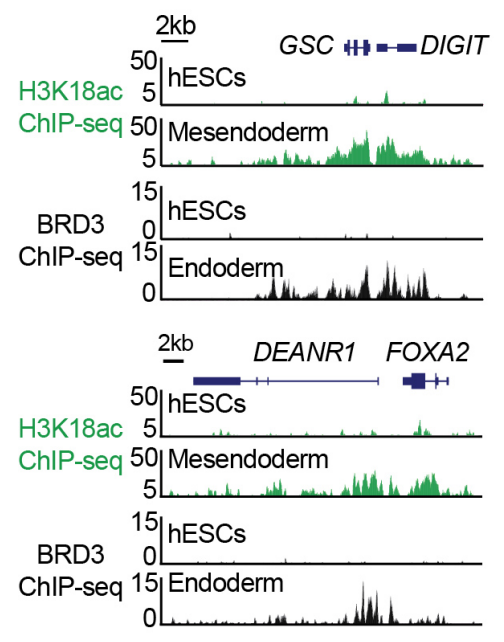

B

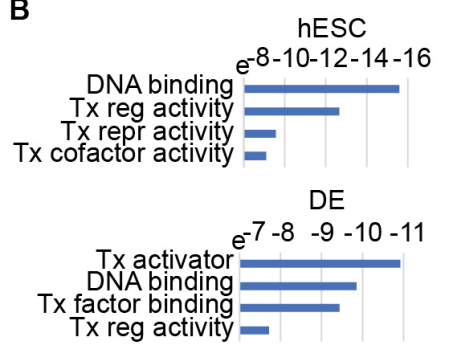

C

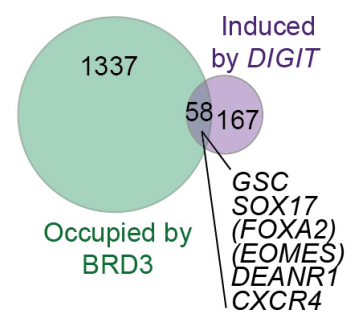

E

F

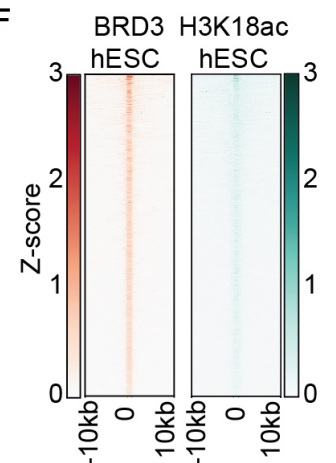

BRD3 H3K18ac

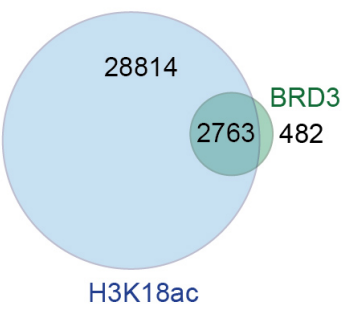

Distance from the center Distance from the center of the peak (bp)

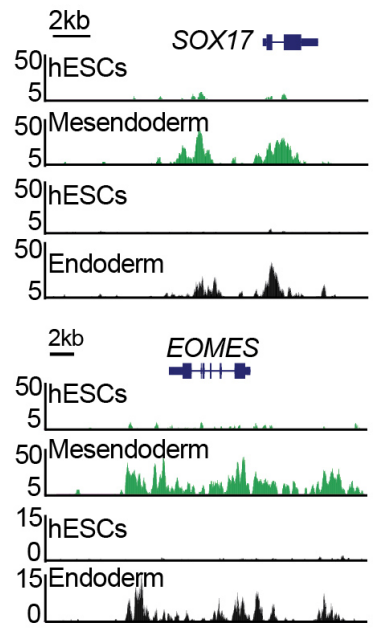

H

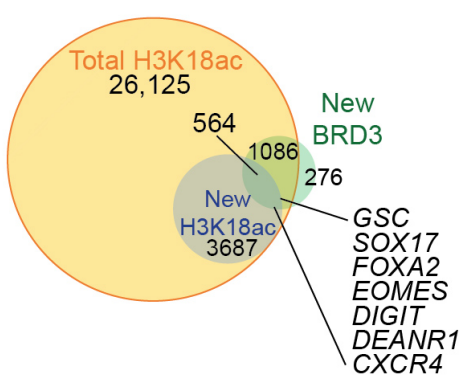

\section{Figure 6. BRD3 interacts with DIGIT-regulated genes on H3K18ac-marked chromatin.}

(A) Genomic distribution of BRD3 in hESCs and after 4 days of definitive endoderm (DE) differentiation. (B) Gene ontology analysis for genes occupied by BRD3. Bars indicate p-value. Tx: transcription. (C) Venn diagram showing the overlap of genes occupied by BRD3 and repressed with depletion of DIGIT (induced by $D I G I T$ ) during endoderm differentiation. Endoderm genes that are regulated by DIGIT and occupied by BRD3 are listed. Genes in parentheses did not meet statistical significance on RNA-seq (FDR <0.01, (Daneshvar et al., 2016) and were validated by qRT-PCR in panel D. * indicates $p<0.05$. (D) qRT-PCR was performed in two independently-derived DIGIT-deficient hESCs lines (Daneshvar et al., 2016) after day 4 of endoderm differentiation. RNA expression is normalized to 1.0 in control cells (green) and compared to two different DIGIT-deficient lines. (E) Venn diagram showing the overlap of regions modified by H3K18ac in mesendoderm and occupied by BRD3 in endoderm differentiation. (F) Heatmaps show co-occupancy of BRD3 and H3K18ac in hESCs and definitive endoderm/mesendoderm (DE/ME). 
H3K18ac ChIP-seq analysis was performed on day 2 of mesendoderm differentiation induced by BMP4 and activin (Dixon et al., 2015). (G) Example mesendoderm and definitive endoderm genes that are modified by H3K18ac and occupied by BRD3 upon differentiation of hESCs toward mesendoderm and endoderm. (H) Venn diagram showing all regions modified by H3K18ac (yellow), newly modified by H3K18ac in mesendoderm differentiation (blue), and newly occupied by BRD3 with endoderm differentiation (green). The intersection of newly modified H3K18ac regions and newly occupied BRD3 regions contained the indicated endoderm factors. 


\section{BRD3 and H3K18ac are associated across the genome}

We previously found that BRD3 interacts with H3K18ac, and that BRD3 occupies the gene encoding SOX2 in hESCs and the gene encoding GSC with endoderm differentiation, each at sites modified by H3K18ac (Figure 5A-D). We next investigated how BRD3 and H3K18ac interact across the genome. We compared sites of H3K18ac in mesendoderm differentiation (Dixon et al., 2015) with BRD3 occupancy during endoderm differentiation, as many endoderm genes are first activated with formation of mesendoderm (Tada et al., 2005; Vallier et al., 2009). Despite analyzing occupancy under slightly different conditions of differentiation, we found that over $85 \%$ of regions occupied by BRD3 overlap with regions modified by H3K18ac (Figure 6E). In both hESCs and with endoderm differentiation, regions occupied by BRD3 are modified by H3K18ac (Figure 6F and 6G). In addition, approximately 15\% of H3K18ac regions are unique in mesendoderm compared to hESCs, and 564 of these mesendoderm regions are also newly occupied by BRD3 with endoderm differentiation. This group of genes newly marked by H3K18ac and BRD3 with differentiation again includes the key endoderm genes that are also regulated by DIGIT (Figure $6 \mathrm{H}$ ). These results suggest that during differentiation, BRD3 shifts to regions newly modified by H3K18ac, which encompass genes regulated by DIGIT.

\section{DIGIT recruits $B R D 3$ to endoderm genes}

The previous results suggest that DIGIT may act to recruit BRD3 to sites of H3K18ac to induce expression of endoderm genes. To test this hypothesis, we differentiated DIGITdeficient $\left(D / G I T^{g f p / g f p}\right)$ and wildtype hESCs toward endoderm to determine how BRD3 occupancy was affected by depletion of DIGIT. We found that BRD3 occupancy at GSC and FOXA2 (Figure 6G) was impaired with depletion of DIGIT (Figure 7A). As a control, we also assessed BRD3 occupancy at HEXIM2, a gene occupied by BRD3 in hESCs and with endoderm differentiation but not affected by depletion of DIGIT (Figure S7). In contrast to GSC, where we observed reduced BRD3 occupancy in DIGIT-deficient cells, BRD3 occupancy at HEXIM2 was not reduced (Figure 7B). These results suggest that DIGIT is required for recruitment of BRD3 to endoderm genes (Figure 7C). 

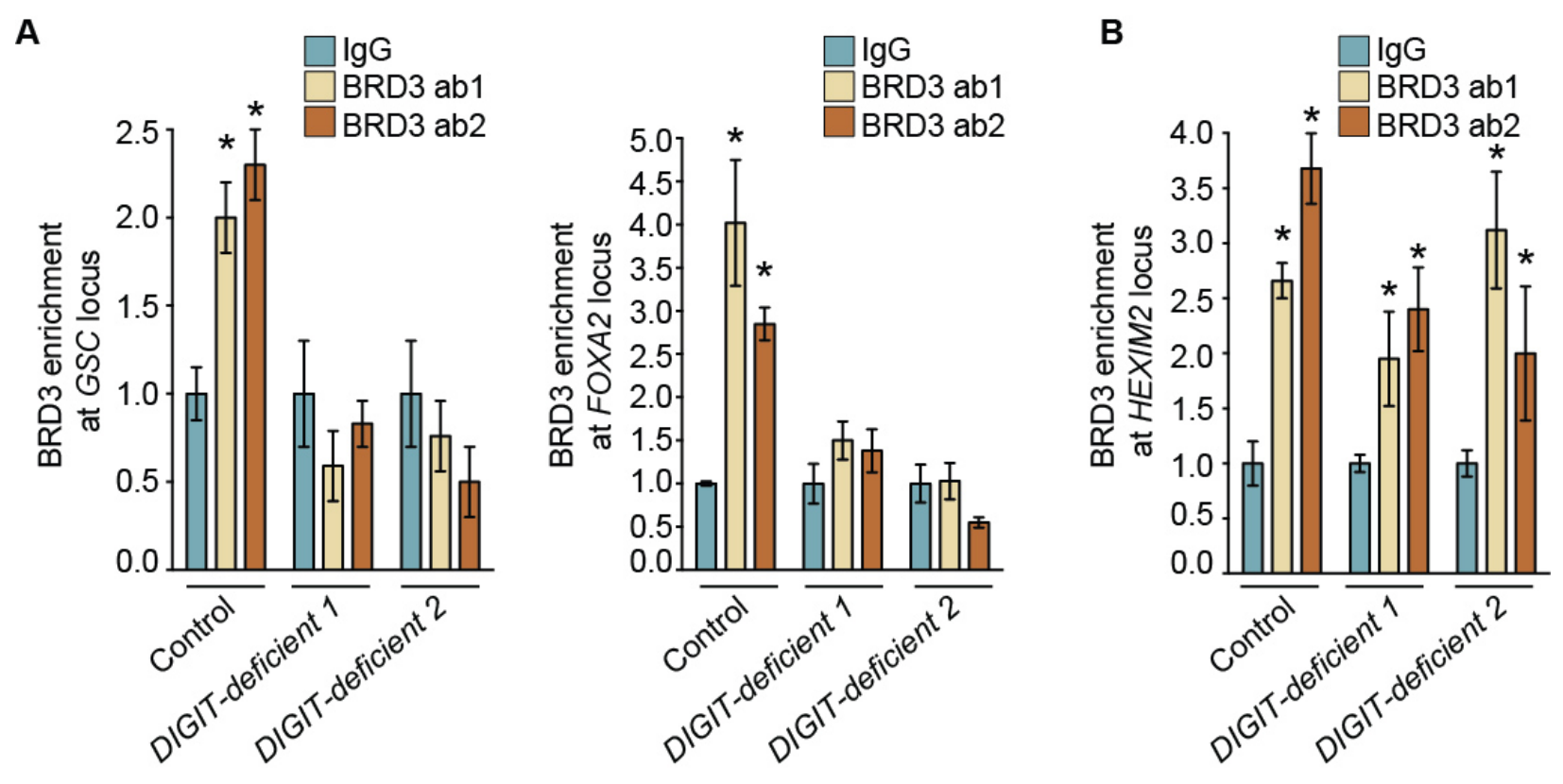

C
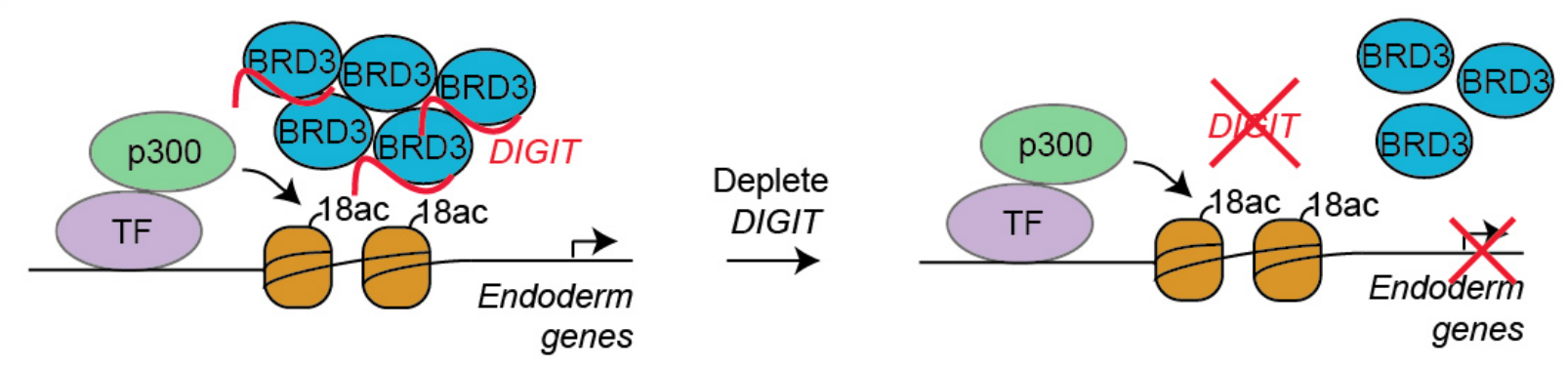

Figure 7. Loss of DIGIT inhibits recruitment of BRD3.

(A) CUT\&RUN was performed followed by qPCR to quantify enrichment of BRD3at the GSC locus (left) and FOXA2 locus (right). Chromatin release was directed using two antibodies recognizing BRD3 (ab1 and ab2). Two independently-derived DIGIT-deficient lines $\left(D / G I T^{g f / g f p}\right)$ were used for each experiment. (B) CUT\&RUN was performed as in (A) using primers that recognize HEXIM2. * indicates $p<0.05$, as calculated by ANOVA and post hoc test, compared to IgG. (C) Schematic showing condensates of BRD3 and DIGIT interacting with $\mathrm{H} 3 \mathrm{~K} 18 \mathrm{ac}$ at the enhancer of an endoderm gene to induce gene expression. H3K18 is acetylated by CBP/p300 following recruitment by transcription factors (TF) (Ito et al., 2000; Jin et al., 2011). In the absence of DIGIT, BRD3 is not able to bind the enhancer, and the endoderm gene is not activated. 


\section{Discussion}

Many IncRNAs interact with proteins to regulate gene expression. The interactions initially identified were found to repress gene expression, in the case of XIST through the interaction with YY1 (Jeon and Lee, 2011) and for HOTAIR and ANRIL through interaction with the polycomb repressive complexes (PRC) (Rinn et al., 2007; Yap et al., 2010). Additional investigations revealed that IncRNAs also partner with proteins to induce gene expression (Bose et al., 2017; Postepska-lgielska et al., 2015). Here we demonstrate that DIGIT interacts with BRD3 proteins in phase-separated condensates to regulate gene expression and endoderm differentiation. BRD3 binds H3K18ac, and during endoderm differentiation, BRD3 shifts to occupy enhancers within domains of H3K18ac. BRD3 can co-occupy genes with H3K18ac independent of DIGIT (Figure 7B and S7), but BRD3 requires DIGIT to occupy regions of H3K18ac near a specific subset of genes (Figure 7A and $7 \mathrm{C}$ ). Thus, the interaction with DIGIT determines the specificity of a set of BRD3 targets, through which BRD3 regulates endoderm differentiation.

$D I G I T$ and BRD3 cooperate to promote expression of key endoderm genes. DIGIT is divergently transcribed from GSC, and activation of GSC can, at least partially, rescue endoderm differentiation (Daneshvar et al., 2016). Results from this study show that DIGIT interacts with BRD3 to control GSC expression and suggest that the interaction between DIGIT and BRD3 also regulates additional endoderm and mesendoderm genes. Thus, through interaction with BRD3, DIGIT expands its influence beyond the immediate vicinity where it is transcribed.

BRD4 forms phase-separated condensates in association with Mediator to regulate gene expression (Sabari et al., 2018), and BRD2, BRD3, and BRD4 each form distinct phase-separated condensates during endoderm differentiation. DIGIT preferentially interacts with BRD3, but there are likely to be other IncRNA partners of BRD3, as well as IncRNAs that preferentially interact with BRD2 and BRD4. The effect of IncRNA-BET family protein interactions on the formation or stability of phase-separated condensates is unclear and will need to be addressed in future experiments. The IncRNA NEAT1 interacts with the protein NONO to promote phase-separated paraspeckles (Yamazaki et al., 2018), and the IncRNA MALAT1 is found in phase-separated nuclear speckles (Hutchinson et al., 2007). The interaction between DIGIT and BRD3 now demonstrates a role for IncRNAs in transcriptional phase-separated condensates.

BRD4 preferentially occupies enhancers in hESCs, while BRD2 and BRD3 preferentially occupy promoters (Di Micco et al., 2014; Engelen et al., 2015). We observe this same bias for BRD3 occupancy at promoters in hESCs, where BRD3 is dispensable. However, with endoderm differentiation, where BRD3 is required, BRD3 shifts to enhancers. These findings suggest enhancer occupancy may be a path through which BRD3 activates developmental regulators and BET family proteins regulate gene expression. 
BRD3 interacts most intensely with H3K18ac, a modification catalyzed by CBP/p300 (Jin et al., 2011). CBP/p300 is also responsible for H3K27ac, but H3K27ac showed $<10 \%$ enrichment for BRD3 binding compared to H3K18ac (data not shown), suggesting that BRD3 has minimal affinity for H3K27ac. In mouse endoderm differentiation, activin signaling leads to increased H3K18ac at the Gsc gene (Xi et al., 2011). Acetylation of H3K18 at Gsc requires both Smad4 and TRIM33, each of which interacts with Smad2/3 in response to activin signaling. These findings suggest that genome occupancy by Smad2/3 at new enhancers leads to recruitment of CBP/p300 (Janknecht et al., 1998; Pouponnot et al., 1998), induction of H3K18ac, and binding of of the BRD3-DIGIT complex to drive expression of Gsc and other Smad2/3 target genes.

BRD2, BRD3, and BRD4 are ubiquitously expressed and have non-overlapping functions in many cell types (Houzelstein et al., 2002; Paillisson et al., 2007; Shang et al., 2009). Our findings indicate that the interaction between BET family proteins and IncRNAs help specify gene targets. These findings suggest that interactions with different IncRNAs may be responsible for determining different subsets of genes regulated by $B E T$ family proteins in different cell types. While we propose that BET family proteins may bind several different IncRNAs species, this binding is limited, as we do not see evidence of broad interaction between BRD3 and polyA RNAs. The interaction with BET family proteins is also not limited to polyA RNAs, as enhancer (e) RNAs can also bind BET family proteins (Rahnamoun et al., 2018). It remains unclear how interactions between BET family proteins and noncoding RNAs regulate gene expression. BRD4 mediates pause release (Liu et al., 2014), while BRD2 and BRD3 show nucleosome remodeling activity to promote processivity of RNA polymerase (LeRoy et al., 2008). Depletion of DIGIT suggests that one mechanism of regulation may be at the level of recruitment of BET family proteins, but interaction with IncRNAs could also regulate the activity of BET family proteins. Further studies are needed to understand the full breadth of interactions between BET family proteins and IncRNAs and how these interactions regulate gene expression, mechanisms which likely control numerous cell functions in development and disease.

\section{Materials and Methods}

\section{Embryonic stem cell culture and differentiation}

H1 (WA01) cells (WiCell) were cultured in feeder-free conditions in mTeSR1 (Stem Cell Technologies) and passaged by Accutase (Stem Cell Technologies) as described (Daneshvar et al., 2016). Endoderm differentiation was induced with $50 \mathrm{ng} / \mathrm{mL}$ Activin A (R\&D Systems) in RPMI with B27 supplement (Thermo Fisher Scientific). Differentiation of hESCs on micro-patterned slides was performed as described (Deglincerti et al., 
2016b; Warmflash et al., 2014). Briefly, hESCs were dissociated into single cells using Accutase and plated on micropatterned slides (Cytoo) that were coated with laminin-521 (BioLamina) as described. Differentiation toward germ layers was induced by addition of $50 \mathrm{ng} / \mathrm{mL}$ of BMP4 (R\&D Systems) to mTeSR1 media. Cells were fixed and immunostained. Immunofluorescence microscopy was performed on an EVOS FL Cell Imaging System (Thermo Fisher Scientific).

\section{S1m aptamer-assisted RNA pull-down}

Plasmids expressing DIGIT, DIGIT-4xS1m, and scramble-DIGIT (SCRM-4xS1m) were transiently transfected into $3 \times 10^{6} \mathrm{H} 1$ cells by lipofectamine 3000 (Thermo Fisher). Cells were differentiated toward definitive endoderm for three days. Cells were washed with DPBS and irradiated with $400 \mathrm{~mJ}$ of energy on ice in a UV cross-linker (Stratalinker). Nuclei of the UV cross-linked cell were isolated by suspending the cells in a hypotonic buffer ( $20 \mathrm{mM}$ Tris- $\mathrm{HCl} \mathrm{pH} \mathrm{7.4,} 10 \mathrm{mM} \mathrm{NaCl}, 3 \mathrm{mM} \mathrm{MgCl}$ ) for 15 minutes, adding NP40 to a final concentration of $0.5 \%$, and then centrifuging for 10 minutes at $850 \mathrm{~g}$. Nuclei were lysed in lysis buffer $(150 \mathrm{mM} \mathrm{KCl}, 25 \mathrm{mM}$ Tris- $\mathrm{HCl} \mathrm{pH}$ 7.4, $5 \mathrm{mM}$ EDTA, $5 \mathrm{mM}$ $\mathrm{MgCl}_{2}, 1 \% \mathrm{NP}-40,0.5 \mathrm{mM}$ DTT, Roche mini-tablet protease inhibitor, and $100 \mathrm{U} / \mathrm{mL}$ RNAseOUT), and debris was cleared by centrifugation at $16000 \mathrm{~g}$. The supernatant containing the nuclear lysate was then cleared with $50 \mu \mathrm{L}$ of Avidin Agarose beads (Thermo Fisher, catalog number: 20219) to deplete the lysate from biotin (Leppek and Stoecklin, 2014). The cleared lysate was incubated with $150 \mu \mathrm{L}$ of Streptavidin C Dynabeads (Thermo Fisher) for 4 hours on a rocker at $4^{\circ} \mathrm{C}$. Beads were collected using a magnet and washed three times with a wash buffer of the same composition as the lysis buffer, except $\mathrm{KCl}$ was increased to $350 \mathrm{mM}$. To release the proteins, beads were incubated with RNase $A$ and resuspended in 2x LDS sample buffer. The entire lysates were resolved on a polyacrylamide gel. Segments of the gel between 30 to $200 \mathrm{kDa}$ were excised and analyzed by mass spectrometry. Mass spectrometry was performed at Harvard Medical School Taplin Mass Spectrometry Core. Analysis of the proteomic data was performed using the Crapome proteomic analysis pipeline (Mellacheruvu et al., 2013).

\section{Pull-down of cross-linked polyadenylated RNA and protein complexes}

The pull-down of polyadenylated RNAs was performed as described before (Castello et al., 2016). Ten million hESCs were differentiated toward endoderm for 3 days. Cells were UV cross-linked as described above. The nuclear fraction was isolated as described above. Nuclei were lysed in lysis/binding buffer $(20 \mathrm{mM}$ Tris-HCl pH 7.5, 500 $\mathrm{mM} \mathrm{LiCl,} \mathrm{0.5 \%} \mathrm{LiDS,} 1 \mathrm{mM}$ EDTA, $5 \mathrm{mM}$ DTT). The lysate was then incubated with 200 $\mu \mathrm{L}$ of oligo-dT 25 Magnetic Beads (NEB, S1419S) for 10 minutes. The beads were washed two times with wash buffer $1(20 \mathrm{mM}$ Tris-HCl pH 7.5, $500 \mathrm{mM} \mathrm{LiCl}, 0.1 \% \mathrm{LiDS}$, $1 \mathrm{mM}$ EDTA, $5 \mathrm{mM}$ DTT), two times with wash buffer $2(20 \mathrm{mM}$ Tris- $\mathrm{HCl} \mathrm{pH} 7.5,500$ $\mathrm{mM} \mathrm{LiCl}, 1 \mathrm{mM}$ EDTA), and one time with low salt buffer $(20 \mathrm{mM}$ Tris- $\mathrm{HCl} \mathrm{pH}$ 7.5, 200 
$\mathrm{mM}$ LiCl, $1 \mathrm{mM}$ EDTA). Proteins were released by addition of $5 \mu \mathrm{g}$ of RNase A (Sigma) in RNA digestion buffer $(20 \mathrm{mM}$ Tris- $\mathrm{HCl} \mathrm{pH} 7.5,30 \mathrm{mM} \mathrm{NaCl}, 5 \mathrm{mM} \mathrm{MgCl}, 2 \mathrm{mM}$ DTT, 1 tablet/10 mL Mini Complete Protease Inhibitors, EDTA-free). For RNase digested control, RNase A was added to the low salt buffer wash.

\section{Transfection and genome editing}

For transfection, hESCs were dissociated by Accutase and resuspended in buffer $1 \mathrm{M}$ nucleofection buffer ( $5 \mathrm{mM} \mathrm{KCl}, 15 \mathrm{mM} \mathrm{MgCl}_{2}, 120 \mathrm{mM} \mathrm{Na} 2 \mathrm{HPO}_{4} / \mathrm{NaH}_{2} \mathrm{PO}_{4} \mathrm{pH} 7.2,50$ $\mathrm{mM}$ Mannitol) and transfected in a Nucleofector 4D (Lonza) (Chicaybam et al., 2013). For genome editing, $3 \mu \mathrm{g}$ of the homology construct and $1 \mu \mathrm{g}$ of the Cas9/gRNA construct were co-transfected. For the generation of BRD3 knockout lines, cells were treated with $0.5 \mu \mathrm{g} / \mathrm{mL}$ puromycin for 8 days starting 48 hours after transfection. Puromycin-resistant colonies were picked and transferred to 48-well plates. For insertion of mEGFP into BRD3, 72 hours after transfection of constructs, cells were sorted by flow cytometry using a FACSAria flow cytometer. For the generation of hESCs that stably express NLS-mEGFP, we inserted a DNA sequence expressing NLSmEGFP under an EF1a promoter and puromycin resistance gene under an RPBSA into the $\mathrm{H} 1$ genome using the Sleeping Beauty Transposon System (Kowarz et al., 2015). Cells were treated with puromycin for 8 days and expression of NLS-mEGFP was confirmed by fluorescence microscopy.

Expression and purification of FLAG-BRD3, FLAG-mEGFP-BRD3, and FLAG-mEGFP proteins

The cDNA for the short isoform of human BRD3 (Dharmacon, clone ID: 4856840) was used to generate the long isoform of BRD3. The extra sequence was generated by PCR amplification from hESC genomic DNA and added by Gibson assembly (NEB). The long isoform of BRD3 with N-terminal mEGFP (FLAG-mEGF-BRD3) and the short isoform of BRD3 (FLAG-BRD3) were subcloned into pFastBac1 Baculovirus expression plasmid, each with a single N-terminal FLAG-tag. The FLAG-mEGFP-BRD3 fusion protein containing the long isoform of BRD3 was created with a 7 amino acid linker sequence (FLAG-GSAAAGS-mEGFP-GSAAAGS-BRD3). The FLAG-BRD3 fusion created using the short isoform of BRD3 was created without a linker between the FLAG sequence and the start of BRD3.

One liter of Sf9 cells infected with P3 viral particles expressing each construct was grown in ESF 921 medium (Expression Systems) at $28^{\circ} \mathrm{C}$. Forty two hours post infection, FLAG-tagged proteins were affinity purified from the nuclear extract as described (Abmayr et al., 2006; Grau et al., 2011). All steps were carried out at $4{ }^{\circ} \mathrm{C}$. In brief, $500 \mu \mathrm{L}$ of equilibrated anti-FLAG M2 affinity gel (50\% slurry, Sigma) was added to isolated nuclei in BC600 (20 mM HEPES pH 7.9, 20\% glycerol, $1.5 \mathrm{mM} \mathrm{MgCl}_{2}, 0.6 \mathrm{M}$ $\mathrm{KCl}, 0.2 \mathrm{mM}$ EDTA, $0.2 \mathrm{mM}$ PMSF, $0.5 \mathrm{mM}$ DTT, 0.05\% NP-40, and Complete 
Protease Inhibitor Cocktail (Roche)), after 3-4 hrs the beads were passed through Econo-Pac chromatography columns (Bio-Rad) and washed with $20 x$ bead volume of wash buffer in the following order: BC600(x2), BC1200, BC600, BC300 and eluted twice by incubation with $250 \mu \mathrm{L}$ of $400 \mu \mathrm{g} / \mathrm{mL}$ FLAG peptide in BC300 (without NP-40). Each elution was carried out for 20 min. Eluted protein was concentrated using Amicon Ultra centrifuge filters. The concentration of the complex was determined by Bicinchoninic acid (BCA) assay (Thermo Fisher).

FLAG-mEGFP (FLAG-GSAAAGS-mEGFP-GSAAAGS) was also cloned into pFastBac1 and purified as follows. After 42 hrs of infection with P3 viral stock, cells were lysed and flash-frozen in BC500 (50 mM Tris pH 8.0, $0.5 \mathrm{M} \mathrm{NaCl}, 20 \%$ glycerol, $0.05 \%$ NP-40, 0.2 mM EDTA, $0.2 \mathrm{mM}$ PMSF, $0.5 \mathrm{mM}$ DTT, and Roche complete protease inhibitor tablets). The frozen extract was thawed, spun down at 14,000 $\mathrm{g}$ for $30 \mathrm{~min}$, and the supernatant was incubated with $500 \mu \mathrm{L}$ of equilibrated M2-agarose beads for 3-4 hrs. Purification was performed using Econo-Pac chromatography columns as described above and elsewhere (Grau et al., 2011).

\section{Fluorescence recovery after photobleaching (FRAP)}

For FRAP experiments, hESCs were grown and differentiated on coverslip bottom tissue culture dishes (FluoroDish, World Precision Instruments) and imaged using a Nikon A1R confocal inverted microscope. Photobleaching was performed using the $488 \mathrm{~nm}$ laser at $95 \%$ power. A circular region of interest (ROI) with a radius of $1.5 \mu \mathrm{m}$ was defined around a single BRD3 punctum. Images were acquired at indicated times. The fluorescence intensity of the puncta were measured by ImgeJ. As a control experiment, the same setup was used except that the photobleaching step was eliminated.

\section{Histone modification arrays}

Modified Histone arrays (Active Motif) were used as described (Saltzman et al., 2018) to identify the histone targets of BRD3. The arrays were washed one time in PBST (PBS, $0.05 \% \mathrm{v} / \mathrm{v}$ Tween-20), blocked with skim milk (5\% w/v in PBST) for 1 hour, and washed with BSA ( $3 \% \mathrm{w} / \mathrm{v}$ in PBST). Arrays were incubated overnight at $4^{\circ} \mathrm{C}$ in binding buffer (PBST, 0.45\% w/v BSA, $0.5 \mathrm{mM}$ EDTA, $0.1 \mathrm{mM}$ DTT, 10\% v/v glycerol) with $100 \mathrm{nM}$ of each protein (FLAG-mEGF-BRD3 long isoform, FLAG-BRD3 short isoform, or FLAGmEGFP). Arrays were then probed with the primary (anti-FLAG) and secondary (antimouse lgG) antibodies. The arrays were incubated in Western Blotting Luminol Reagent (Santa Cruz) and exposed to autoradiography film. Developed films were scanned and analyzed with ArrayAnalyze software (Active Motif). 


\section{Chromatin immunoprecipitation (ChIP)}

Chromatin immunoprecipitation was performed as described (Daneshvar et al., 2016). Approximately 6 million cells per IP were cross-linked with formaldehyde and sheared using a Covaris sonicator. IPs were performed with $1.5 \mu \mathrm{g}$ of antibody per IP.

Cleavage Under Targets and Release Using Nuclease (CUT\&RUN) to quantify DNA enrichment

CUT\&RUN was performed as described (Skene and Henikoff, 2017; Skene et al., 2018) with following modifications: 1) Dissociated cells were cross-linked by resuspension in a cross-linking buffer (11\% Formaldehyde, $0.1 \mathrm{M} \mathrm{NaCl}, 1 \mathrm{mM}$ EDTA, $0.5 \mathrm{mM}$ EGTA, 50 mM HEPES) for 10 minutes and quenched in $125 \mathrm{mM}$ glycine in DPBS. 2) Tween-20 was added to all wash buffer at a final concentration of $0.2 \%$. 3) Bovine Serum Albumin (BSA) was added to wash buffers at the final concentration of $0.25 \% \mathrm{w} / \mathrm{v}$. 4) CUT\&RUN fragments were reverse cross-linked in $65^{\circ} \mathrm{C}$ for 6 hours before DNA extraction. Recombinant Protein A fused to MNase was a gift from Steven Henikoff (Fred Hutchinson Cancer Research Center).

Cleavage Under Targets and Release Using Nuclease to isolate chromatin-associated RNA (CUT\&RUNER)

This assay was performed similarly to cross-linked CUT\&RUN, as described above, with following modifications: 1) Superase-In RNase inhibitor (Thermo Fisher) was added to all buffers at a final concentration of $20 \mathrm{U} / \mathrm{mL}$. 2) In the targeted digestion step, barium chloride was added at a final concentration of $10 \mathrm{mM}$ along with $\mathrm{CaCl}_{2}$ at a final concentration of $2 \mathrm{mM}$. 3) RNase A was removed from the 2x STOP buffer. 4) SDS was removed from the reverse cross-linking step to avoid its precipitation with barium (Putnam and Neurath, 1944).

\section{Immunostaining}

Cells were fixed in paraformaldehyde (4\% in DPBS). Cells were blocked and permeabilized in a blocking buffer $(0.1 \%$ BSA, 3\% normal donkey serum, $0.1 \%$ Triton X100 in PBS). After incubation with antibodies, cells were washed three times in a wash buffer (0.1\% Tween-20 in DPBS) and one time in DPBS. Nuclear staining was performed by addition of Hoechst to the last wash buffer.

In vitro droplet assay

The concentration of the recombinant mEGFP-BRD3 and mEGFP were adjusted to varying concentrations with indicated final salt concentrations and 10\% PEG-8000 (crowding agent) in Buffer D (50 mM Tris- $\mathrm{HCl} \mathrm{pH} \mathrm{7.5,10 \%} \mathrm{glycerol,} \mathrm{1mM} \mathrm{DTT).} \mathrm{The}$ protein solution was then loaded onto a homemade chamber slide (a microscope glass 
slide with a coverslip attached by two parallel strips of double-sided tape). Slides were then imaged with an Andor confocal microscope with a 150x objective.

\section{In vitro transcription and fluorescent labeling of RNA}

The cDNA encoding full-length spliced DIGIT was in vitro transcribed using the HighScribe T7 High Yield RNA synthesis kit (NEB, E2040s). Cyanine 3-UTP (Enzo Life Sciences, ENZ-42505) was added to the reaction at the final concentration of $2.5 \mathrm{mM}$. Synthesized RNA was purified and tested for integrity and fluorescence on a bleach agarose gel (Aranda et al., 2012).

\section{Sequential immunostaining and single molecule RNA-FISH}

Cells were grown and differentiated on matrigel coated coverslips (Daneshvar et al., 2016). Cells were fixed in $3.7 \%$ formaldehyde in DPBS, followed by permeabilization in $1 \%$ Triton $\mathrm{X}-100$. After staining with primary and secondary antibodies, cells were fixed in the fixation buffer one more time. Cells were then washed with smFISH wash buffer (10\% v/v formamide, 2X SSC in DPBS) and hybridized with smFISH probes (Biosearch Technologies) in hybridization buffer $(0.1 \mathrm{~g} / \mathrm{mL}$ dextran sulfate, $10 \% \mathrm{v} / \mathrm{v}$ deionized formamide, 2x nuclease-free SSC, in nuclease-free water) overnight, and washed three times in wash buffer and one time in $2 x$ SSC, before cells were stained with Hoechst and mounted on slides.

Slides were imaged on a StellarVision inverted microscope (Optical Biosystems, model SV20HT) using a Nikon CFI S Plan Fluor ELWD 0.45NA 20xC air objective. Synthetic Aperture Optics (SAO) illumination was achieved with dedicated $473 \mathrm{~nm}, 532 \mathrm{~nm}$, and $660 \mathrm{~nm}$ laser lines (Laser Quantum) and Hoechst was excited with a $365 \mathrm{~nm}$ LED. Exposure times were determined for a randomly chosen area of cells near the center of the coverslip, then nine single-Z-plane fields of view (FOV) $(333 \mu \mathrm{m} \times 333 \mu \mathrm{m})$ were automatically captured in an outwards clockwise spiral from the first FOV stage position. Each channel was acquired sequentially in the following order: $365 \mathrm{~nm}, 473 \mathrm{~nm}, 532$ $\mathrm{nm}, 660 \mathrm{~nm}$. Image-based autofocus on the DAPI channel was used to adjust focus after stage movements. Images were captured with an Andor sCMOS Zyla 4.2 Plus camera and raw image data was reconstructed using SV Recon software (Optical Biosystems, version 2.9.118). The pixel size in the final $4096 \times 4096$ pixel reconstructed image is $81 \mathrm{~nm}$.

A total of 2206 nuclei from $1 \mathrm{~mm}^{2}$ area were included for analysis of DIGIT IncRNA, GSC mRNA, and BRD3 protein as follows. First, the centroid pixel and masked area of a total of 379 DIGIT and 2412 GSC smFISH spots were identified by SV Quant (Optical Biosystems, version 7.03) using intensity, modulation, and shape descriptor thresholds. All subsequent analysis was done in FIJI. To isolate nuclear BRD3 condensate areas for analysis, thresholded DAPI regions of interest (ROIs) were overlaid on BRD3 images and all extranuclear BRD3 signal was removed. DAPI-restricted BRD3 areas were 
thresholded and overlaid separately to each of the DIGIT or GSC spot centroid maps from SV Quant to determine colocalization. Colocalization was defined as having the centroid pixel of either a DIGIT or GSC smFISH spot occur inside of a BRD3 ROI.

\section{Plasmids and molecular cloning}

Homology constructs were generated by amplification of homology arms from hESC genomic DNA and cloned into a BamHI/Sall digested PUC19 backbone by Gibson assembly (repliQ HiFi Assembly Mix, Quanta Bio). For the generation of mEGFP expressing hESCs, we first added an NLS to the mEGFP-N1 plasmid. The NLS-mEGFP cassette was then sub-cloned into the Sleeping Beauty pSBbi-Pur plasmid. mEGFP-N1 plasmid was a gift from Michael Davidson (Addgene plasmid \# 54767). pX330-U6Chimeric_BB-CBh-hSpCas9 was a gift from Feng Zhang (Addgene plasmid \# 42230). pSBbi-Pur plasmid was a gift from Eric Kowarz (Addgene plasmid \# 60523). pCMV(CAT)T7-SB100 was a gift from Zsuzsanna Izsvak (Addgene plasmid \# 34879). The 4xS1m construct was a gift from Georg Stoecklin (Heidelberg University).

\section{Co-immunoprecipitation (co-IP)}

Nuclei from 5 million cells were prepared as described above. Nuclei were lysed in a IP lysis/wash buffer (50 mM Tris-HCL PH 7.5, $150 \mathrm{mM} \mathrm{NaCL,} 1 \mathrm{mM}$ EDTA, 1\% Triton X$100,1 \mathrm{x}$ Halt protease inhibitor). Nuclear debris was pelleted by centrifugation at 16000 $g$ for 20 minutes. The supernatant was incubated with $4 \mu \mathrm{g}$ of antibody on a rotator at $4^{\circ} \mathrm{C}$ for 16 hours. $40 \mu \mathrm{L}$ of Dynabeads Protein G (Thermo Fisher, 10003D) was washed in the lysis/wash buffer, incubated in the lysate and antibody mix, and incubated for 1 hour at $4^{\circ} \mathrm{C}$. Beads were precipitated by a magnetic rack and washed three times in lysis/wash buffer. Proteins were eluted by adding $2 x$ sample buffer to the beads and boiling.

\section{Quantification of MNase's DNase and RNase activity}

The DNase and RNase activity of MNase in the presence of different cations was tested as described (Cuatrecasas et al., 1967). Thirty micrograms of salmon sperm DNA (Thermo Fisher, 15632011) or yeast tRNA (Thermo Fisher, AM7119) was used for MNase activity. pA-MNase was added to each reaction to the final concentration of 700 $\mathrm{ng} / \mathrm{mL}$. Reactions were incubated at $37^{\circ} \mathrm{C} .260 \mathrm{~nm}$ absorbance was measured every 3 minutes by a Nanodrop 2000 Spectrophotometer (Thermo Fisher).

\section{$\underline{R N A \text {-immunoprecipitation (RIP) }}$}

RIP was performed as described (Rinn et al., 2007). Nuclear fraction was prepared as described above. Nuclei were then lysed in RIP buffer $(150 \mathrm{mM} \mathrm{KCl}, 25 \mathrm{mM}$ Tris pH 7.4, $5 \mathrm{mM}$ EDTA, $0.5 \mathrm{mM}$ DTT, $0.5 \%$ NP-40, RNase-inhibitor, and protease inhibitor). Nuclear membrane and debris were pelleted by centrifugation at $16,000 \mathrm{~g}$ for 10 minutes. $5 \mu \mathrm{g}$ of each antibody was added to each lysate and incubated in rotator at $4^{\circ} \mathrm{C}$ 
for 3 hours. $40 \mu \mathrm{L}$ of protein G Dynabeads (Thermo Fisher) was added to each reaction and incubated for one hour on a rotator at $4^{\circ} \mathrm{C}$. Beads were precipitated on a magnetic rack and washed three times with RIP buffer. Beads were resuspended and boiled in $2 x$ sample buffer and a reducing agent.

\section{Antibodies}

\begin{tabular}{|c|c|c|c|}
\hline Antigen & Application & Vendor & Catalog number \\
\hline BRD3 & IF & Novus Biologicals & NBP2-14360 \\
\hline BRD3 & ChIP, RIP & Bethyl & A302-367A \\
\hline BRD3 & ChIP, RIP & Bethyl & A302-368A \\
\hline BRD2 & RIP & Bethyl & A700-008 \\
\hline BRD2 & IF & Sigma & PLA0066 \\
\hline BRD4 & RIP, IF & Bethyl & A700-004 \\
\hline $\mathrm{H} 3 \mathrm{~K} 4 \mathrm{me} 3$ & CUT\&RUN & Millipore & CS200580 \\
\hline H3K18ac & CUT\&RUN & Abcam & $a b 1191$ \\
\hline H3K27me3 & CUT\&RUN & Millipore & $07-449$ \\
\hline FLAG-tag & Histone peptide array & Sigma & F3165 \\
\hline SOX17 & Immunofluorescence & R\&D Systems & AF1924 \\
\hline SMAD3 & Co-IP & Abcam & ab28379 \\
\hline P300 & Immunofluorescence & R\&D Systems & AF3789 \\
\hline sox2 & Immunofluorescence & Thermo Fisher Scientific & $14-9811-82$ \\
\hline beta-ACTIN & Immunoblotting & Santa Cruz Biotechnology & sc-47778 HRP \\
\hline GFP & Immunoblotting, IF, IP & Abcam & $a b 1218$ \\
\hline $\begin{array}{l}\text { Donkey anti-rat } \\
\text { Alexa fluor } 647\end{array}$ & $\begin{array}{l}\text { Secondary antibody for } \\
\text { IF }\end{array}$ & Abcam & ab150155 \\
\hline $\begin{array}{l}\text { Donkey anti-goat } \\
\text { Alexa fluor } 594\end{array}$ & $\begin{array}{l}\text { Secondary antibody for } \\
\text { IF }\end{array}$ & Thermo Fisher Scientific & A11058 \\
\hline $\begin{array}{l}\text { Donkey anti- } \\
\text { mouse Alexa } \\
\text { fluor } 488\end{array}$ & $\begin{array}{l}\text { Secondary antibody for } \\
\text { IF }\end{array}$ & Thermo Fisher Scientific & A21202 \\
\hline
\end{tabular}




\section{Chromatin Immunoprecipitation and sequencing (ChIP-seq) analysis}

ChIP-seq was performed as previously described (Daneshvar et al., 2016) for BRD3 in hESCs and after 4 days of endoderm differentiation. ChIP-seq libraries prepared from whole cell extracts were used for background. Duplicate samples were analyzed for each condition. Two replicates of H3K18ac ChIP-seq data for hESCs (H1) and mesendoderm (ME) and control datasets were downloaded from GEO (GSE16256) (Dixon et al., 2015). We mapped the raw reads of combined replicates to human reference genome (hg19) using Bowtie2 (version 2.1.0) (Langmead and Salzberg, 2012) with the following settings: bowtie2 -k2 -N1 -L32 --end-to-end -p 4 --phred33 -x bowtie2_index $-U$ sample.fastq $1>$ sample.sam 2>sample.log. SAM files were converted into bam format using Samtools (Li et al., 2009): samtools view -bS sample.sam > sample.bam. Occupied regions were called using MACS2 (Zhang et al., 2008) with the following settings: macs2 callpeak -t DE68_2reps.bam -c DE_input.bam -f BAM -g $2.9 e 9$-n DE_BRD3 -q 0.01 --nomodel --shiftsize=150 -B --broad --broad-cutoff=0.1 -$S P M R$. We defined regions enriched in endoderm differentiation by using Bowtie2 to call BRD3 peaks in endoderm using BRD3 occupancy in hESCs as background. We then removed any regions that were not called as occupied by BRD3 in endoderm when whole cell extract was used as a background. We performed the same analysis for H3K18ac using the data for hESCs and mesendoderm. Regions occupied by BRD3 in hESCs were defined by comparing BRD3 ChIP-seq data in hESCs to whole cell extract background. We used H3K27ac histone modification (GSE16256) to define active enhancers (Creyghton et al., 2010; Rada-Iglesias et al., 2011). H3K27ac peaks were called using the same methods as for H3K18ac ChIP-seq data. Occupied regions were assigned to a gene if the region was within 10 kilobases upstream of the TSS or overlapped the gene body.

Visualization of regions occupied by BRD3 and modified by H3K18ac and H3K27ac

We generated peak tracks using MACS2 with the following settings: macs2 bdgcmp - $t$ treatment_pileup.bdg -c control_lambda.bdg -o track_logLR.bdg -m logLR - 0.00001 and then converted the output BedGraph formated file into BigWig format based on UCSC toolkit (bedGraphToBigWig) (Kent et al., 2010).

\section{Classification of regions occupied by BRD3}

BRD3 binding regions were classified into four categories based on overlaps with the following regions in the genome: (1) promoters, (2) enhancers, (3) gene body, and (4) others. Promoter regions were defined as the region from upstream $2 \mathrm{~kb}$ to downstream $2 \mathrm{~kb}$ of transcription start sites (TSS). Enhancers were defined by the presence of H3K27ac that did not overlap promoter regions. Gene body was defined from the TSS to transcription termination for each gene annotated in UCSC. Regions were first assigned to promoters. If a region did not overlap by at least $1 \mathrm{bp}$ with a promoter 
region, the region was then evaluated for overlap with enhancer regions. If a region did not overlap a promoter or an enhancer, it was evaluated for overlapping a gene body. Regions that did not overlap with any previous category were classified as other.

\section{Heatmaps of BRD3 and H3K18ac peaks}

Heatmaps of BRD3 and H3K18ac at hESCs and endoderm/mesendoderm represent the read densities of BRD3 and H3K18ac ChIP-seq data at the regions surrounding the summits of BRD3 peaks (from upstream $10 \mathrm{~kb}$ to downstream $10 \mathrm{~kb}$ of the summits) for hESCs and endoderm/mesendoderm respectively. We converted all mapped reads in Bam format into BigWig format using the bamCoverage command from the Deeptool toolkit (version: 3.1) (Ramírez et al., 2016). We then calculated the read densities in each bin using the computeMatrix command from the Deeptool toolkit with the BigWig file as the input. We plotted the heatmaps using the plotHeatmap command from the Deeptool toolkit with the read densities output by computeMatrix.

\section{Distributions of read counts for regions occupied by BRD3 in endoderm}

We used HTseq (v0.6.1) with the setting: ("-r name -a 10 -i gene_id -m union <alignment_file> <gff_file>") (Anders et al., 2015) calculate the number of reads mapped to the regions occupied by BRD3 based on BRD3 ChIP-seq and control ChIPseq. The read counts were normalized by subtracting the number of mapped reads of the control ChIP from the BRD3 ChIP. The distribution graph was plotted based on the lengths of BRD3 binding regions from the smallest number to the largest number.

\section{Gene Ontology (GO) analyses}

GO functional enrichment analysis (Huang et al., 2009a, 2009b) (version 6.7) was performed using the indicated groups of BRD3-associated genes. For analysis in hESCs, the background was defined as all expressed protein coding genes (RPKM>=1) in hESCs. For analysis in endoderm differentiation, the background was defined as all expressed protein-coding genes (RPKM>=1) in endoderm differentiation (GSE75297) (Daneshvar et al., 2016).

\section{Statistical analyses of large-scale data}

The p-values for large-scale comparison were calculated by Wilcoxon-Mann-Whitney test unless otherwise stated.

\section{Acknowledgments}

We would like to thank Ross Tomaino and the Taplin Mass/spec core at Harvard Medical School, the MGH nextGen Sequencing Core, the MGH PMB Microscopy Core Facility, and the HSCl-CRM Flow Cytometry Core Facility at MGH. We thank Tomoe Kitao Ando (Gifu University) for providing consultation in the optimization of the RNA 
pull-down protocol. We are thankful for the continuous help and collaboration from Marc Beal, Josh Ryu, and Ron Cook of Optical Biosystems for their assistance with RNA detection and high-throughput microscopy. This work was supported by $\mathrm{NIH} / \mathrm{NICHD}$ grant R01HD09277302 to A.C.M. 
A

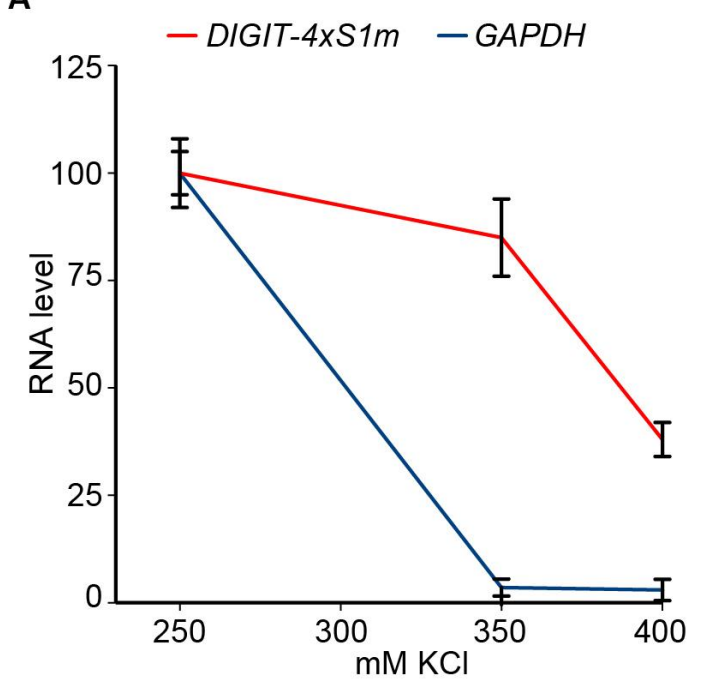

B

\begin{tabular}{|c|c|c|}
\hline Gene & DE rep1 RPKM & DE rep2 RPKM \\
\hline BRD2 & 88.5 & 87.2 \\
\hline BRD3 & 28.0 & 29.5 \\
\hline BRD4 & 44.0 & 40.6 \\
\hline BRDT & 0.9 & 0.8 \\
\hline
\end{tabular}

C

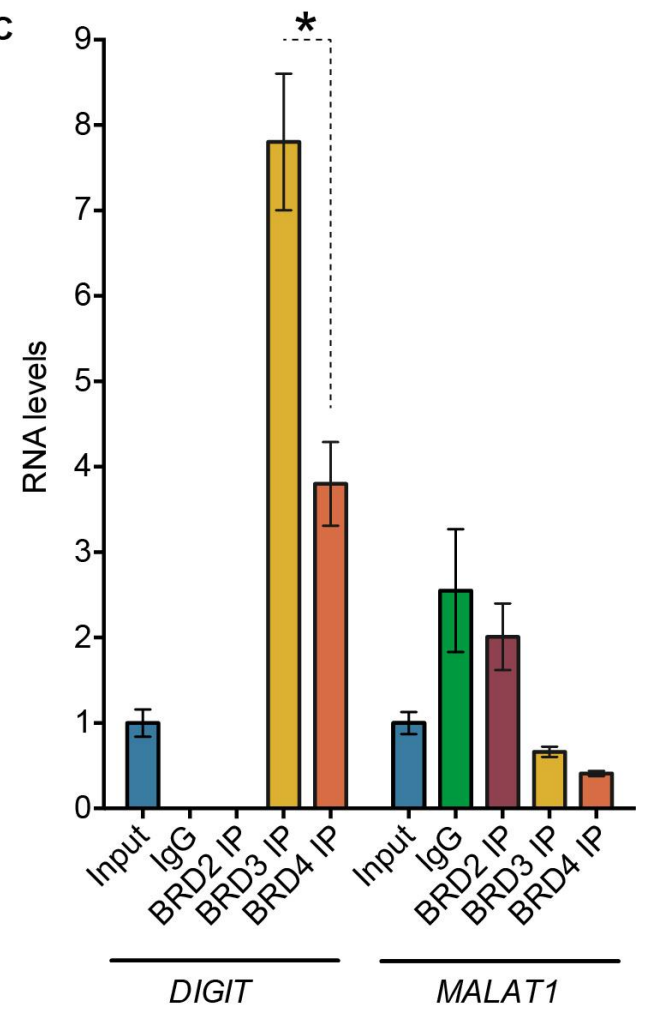

Figure S1. Optimization of washes for RNA pull-down, expression of BRD family members in endoderm, and binding of DIGIT to BRD proteins.

(A) Recovery of DIGIT-4S1m versus endogenous GAPDH mRNA with increasing concentrations of $\mathrm{KCl}$. The amount of RNA recovered with $250 \mathrm{mM} \mathrm{KCl}$ wash conditions is set to 100 for each RNA species. Error bars represent standard deviation of three replicates. (B) The table shows normalized RPKM values for expression of BRD2, BRD3, and BRD4 with endoderm differentiation (Daneshvar et al., 2016). (C) qRT-PCR shows the enrichment DIGIT (left) and MALAT1 (right) following immunoprecipitation of BRD2, BRD3, and BRD4 proteins on day 4 of endoderm differentiation. IgG is used as a non-specific control. Enrichment is quantified relative to GAPDH. * indicates $p<0.05$. 
A
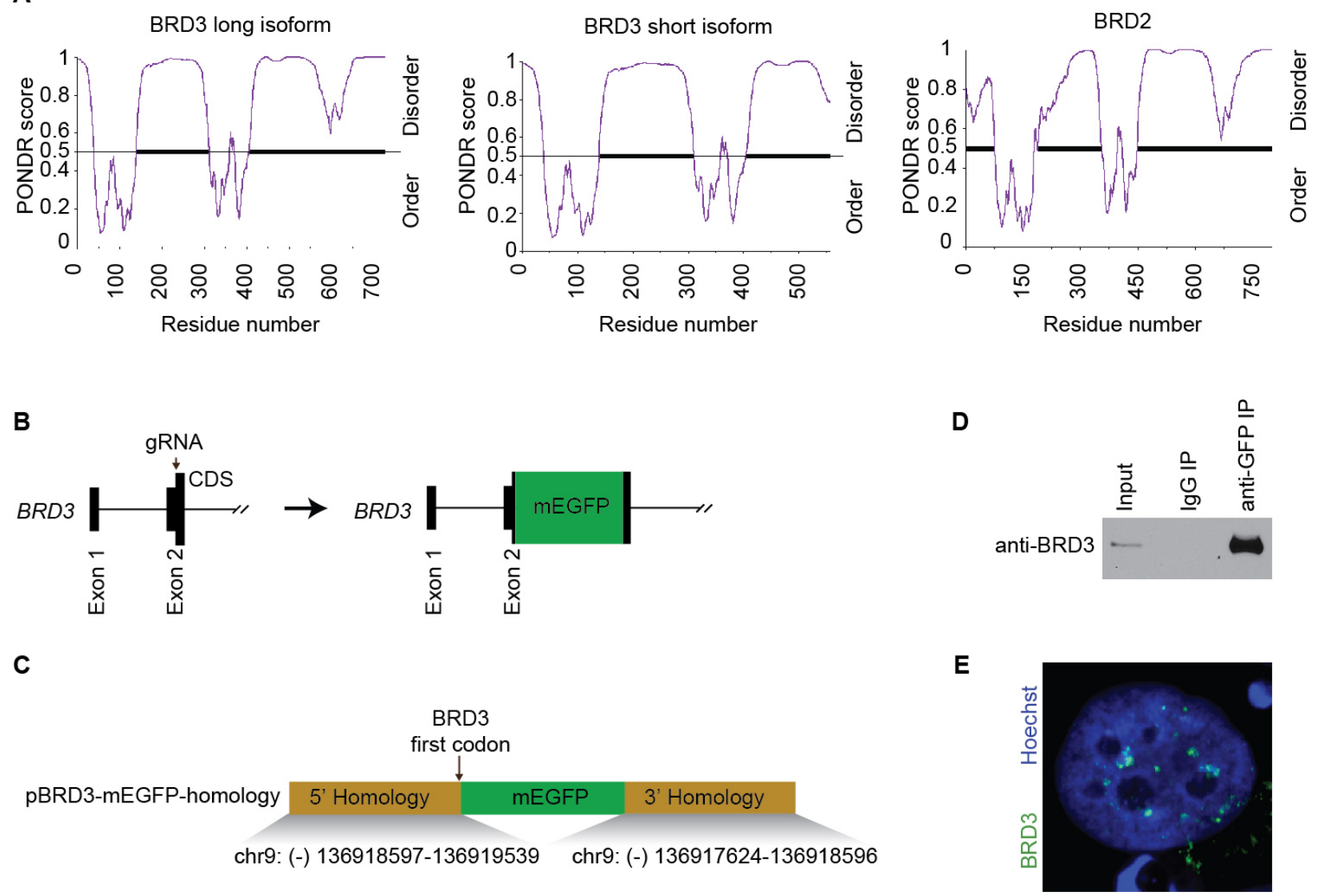

\section{Figure S2. Prediction of ordered/disordered protein structures, strategy for tagging the endogenous BRD3 with mEGFP, and formation of BRD3 puncta in hESCs.}

(A) PONDR VSL2 plots showing the ordered and disordered regions of the long (left) and short (middle) isoforms of BRD3, and BRD2 (right). (B) Creation of mEGFP-BRD3 fusion protein. The cDNA encoding mEGFP was inserted at the $\mathrm{N}$-terminus of $B R D 3$. This terminus is shared by the long and short isoforms of BRD3. The site targeted by gRNA is indicated with an arrow. (C) Design of the homology vector for insertion of mEGFP. The genomic locations of homology arms are indicated. Arrow indicates that mEGFP was inserted after the start codon for BRD3. (D) Immunoblot using anti-BRD3 antibody confirms the generation of mEGFP-BRD3 fused protein. hESCs were lysed and IP was performed using IgG isotype control and an antibody recognizing GFP. Total cell lysates (input) and the IPs were then probed with an anti-BRD3 antibody. (E) Immunofluorescence of an hESC cell showing BRD3 (green) in the nucleus (blue) of the hESCs. 
A

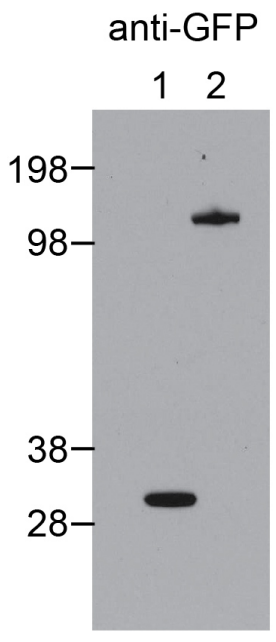

anti-BRD3

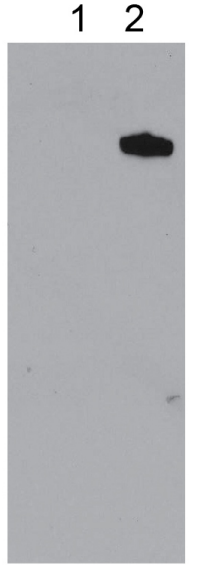

B

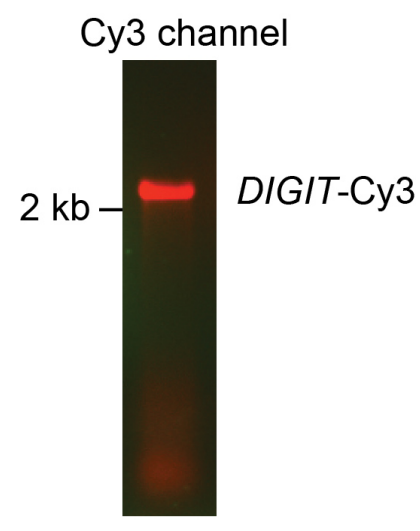

1: Recombinant FLAG-mEGFP

2: Recombinant FLAG-mEGFP-BRD3

Figure S3. Production of recombinant BRD3 and in vitro transcribed and labeled DIGIT.

(A) Immunoblot was performed to detect recombinant FLAG-mEGFP-BRD3 and FLAG-mEGFP using an anti-GFP antibody (left) and an anti-BRD3 antibody (right). (B) Fluorescent detection of the Cy3-labeled DIGIT on a $1 \%$ bleach-agarose gel. 


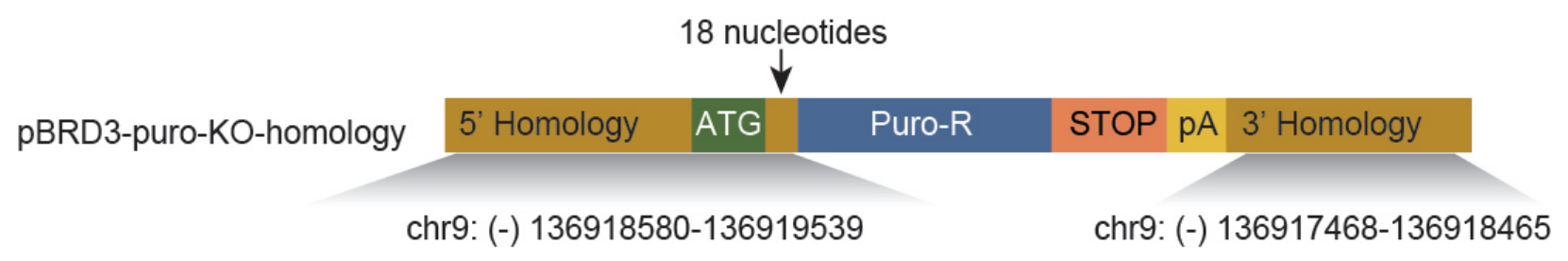

Figure S4. Homology construct for targeting BRD3.

Map of the homology construct for insertion of a puromycin resistance cassette and a stop codon cassette downstream of the sixth codon of the gene encoding BRD3. 
A anti-FLAG antibody

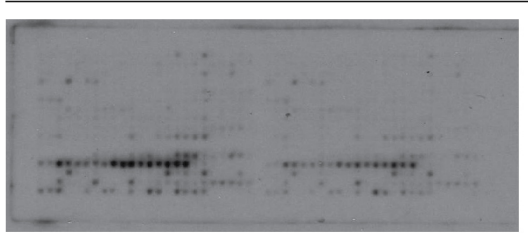

FLAG-mEGFPBRD3 (long isoform)

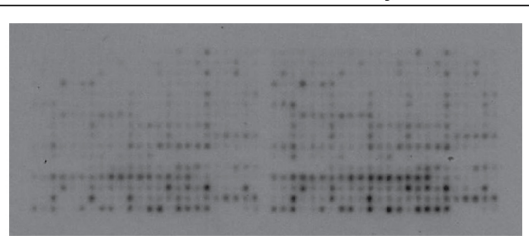

FLAG-BRD3

(short isoform)

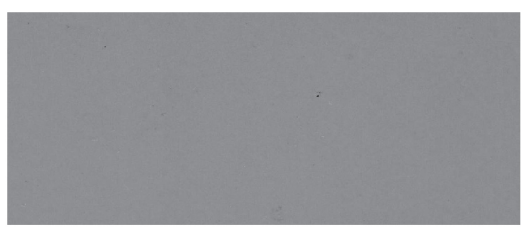

FLAG-mEGFP

\section{B}

\begin{tabular}{|c|c|c|c|c|c|c|c|c|c|c|}
\hline Modification & H3K18ac & H4K20ac & H2AK13ac & H2AK9ac & H2BK15ac & H4K5ac & H4K8ac & H2BK12ac & H4K12ac & H3K9ac \\
\hline Intensity & 0.167 & 0.154 & 0.151 & 0.122 & 0.1125 & 0.112 & 0.108 & 0.10 & 0.055 & 0.051 \\
\hline
\end{tabular}

C

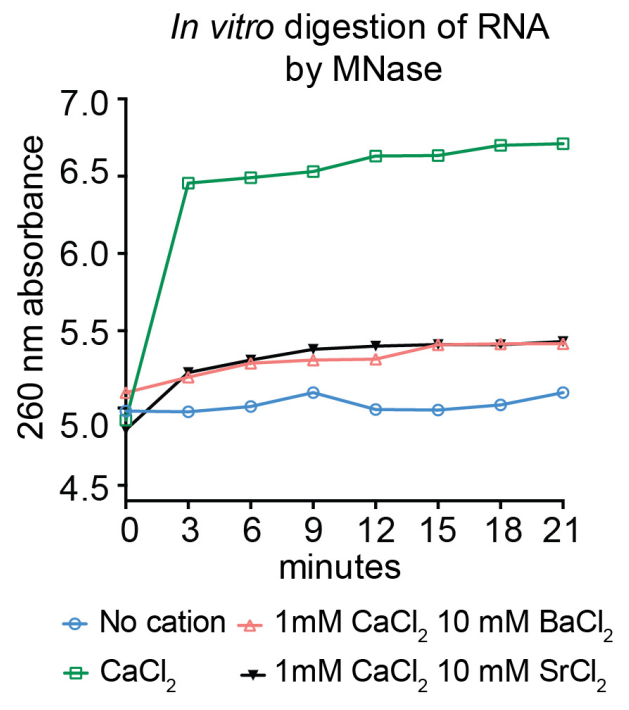

D

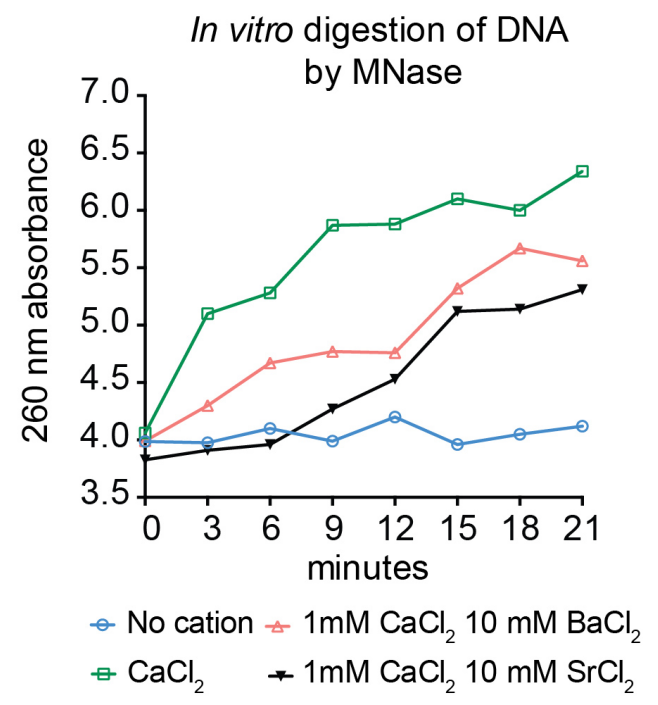

Figure S5. Binding of BRD3 to modified histones and activity of MNase in presence of of $\mathrm{Ba}^{+2}$ and $\mathrm{Sr}^{+2}$ cations.

(A) Peptide arrays show the binding of recombinant BRD3 to histone modifications. (B) Spot intensity of BRD3 (long isoform) binding to the top ten histone modification as quantified by image processing software (see materials and methods). (C) RNase activity of MNase in presence of $\mathrm{Ba}^{+2}$ and $\mathrm{Sr}^{+2}$ cations. (D) DNase activity of MNase in presence of $\mathrm{Ba}^{+2}$ and $\mathrm{Sr}^{+2}$ cations. 
A

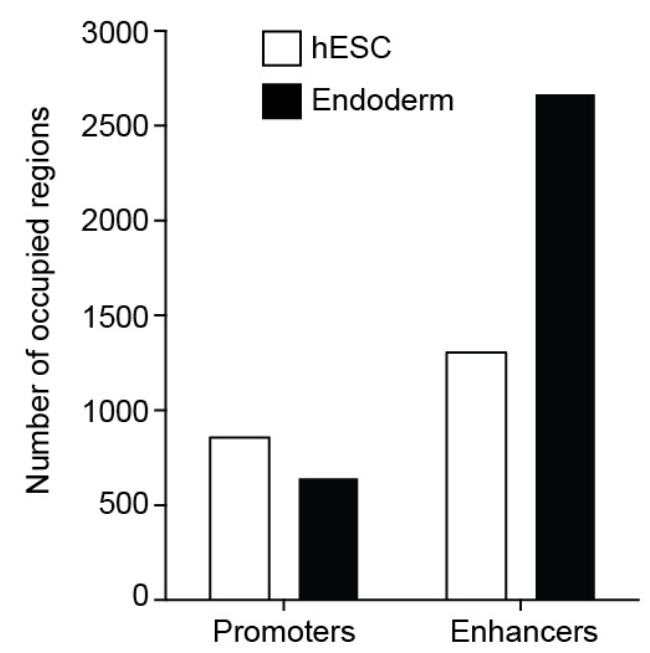

B

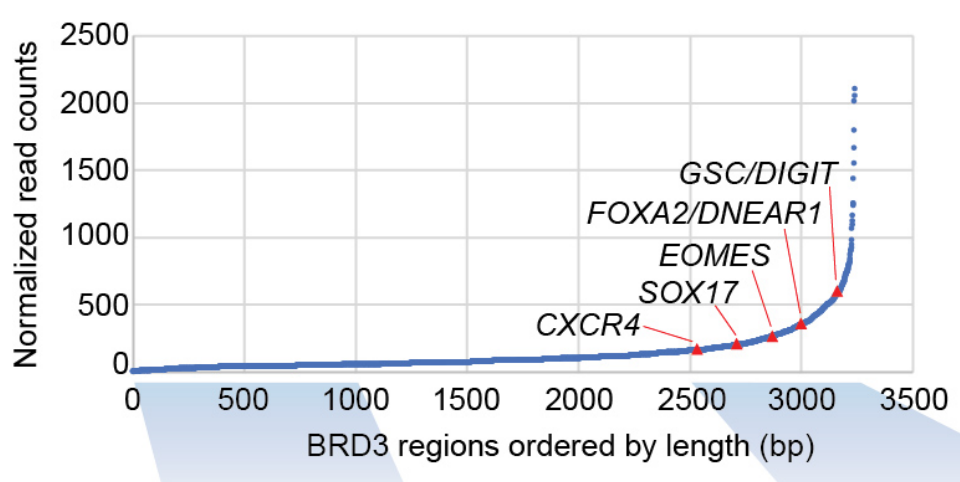

$e^{0} \begin{array}{llllll}0 & -2 & -3 & -4 & -5\end{array}$

Cell-cell signaling

Cell motion $e^{0} \begin{array}{llllllll}0 & -1 & -3 & -4 & -5 & -6 & -7\end{array}$

Embryonic morphog

Pattern specif process

Figure S6. BRD3 occupies endoderm genes and enhancers.

(A) The number of BRD3 regions (y-axis) that contain promoters and enhancers are shown for hESCs (white) and endoderm cells (black). BRD3 regions are defined as containing promoters if the region is located within $2 \mathrm{~kb}$ of a transcription start site (TSS). BRD3 regions are defined as containing enhancers if the region overlaps with enhancers defined by H3K27ac. Regions that contain both promoters and enhancers are counted in both categories. (B) Regions of BRD3 occupancy (3274) from cells on day 4 of endoderm differentiation were ordered by increasing length (x-axis). The normalized read counts for each occupied region are shown on the y-axis. Red triangles indicate the location of endoderm genes. GO analysis was performed for the genes associated with regions of BRD3 occupancy (bottom). The 1000 BRD3 regions with the smallest length (blue shading, left) were associated with 373 genes. The regions of BRD3 occupancy with the largest length (starting with region 2500, blue shading, right) were associated with 348 genes. The top two categories from GO analysis are shown for each set of genes. 


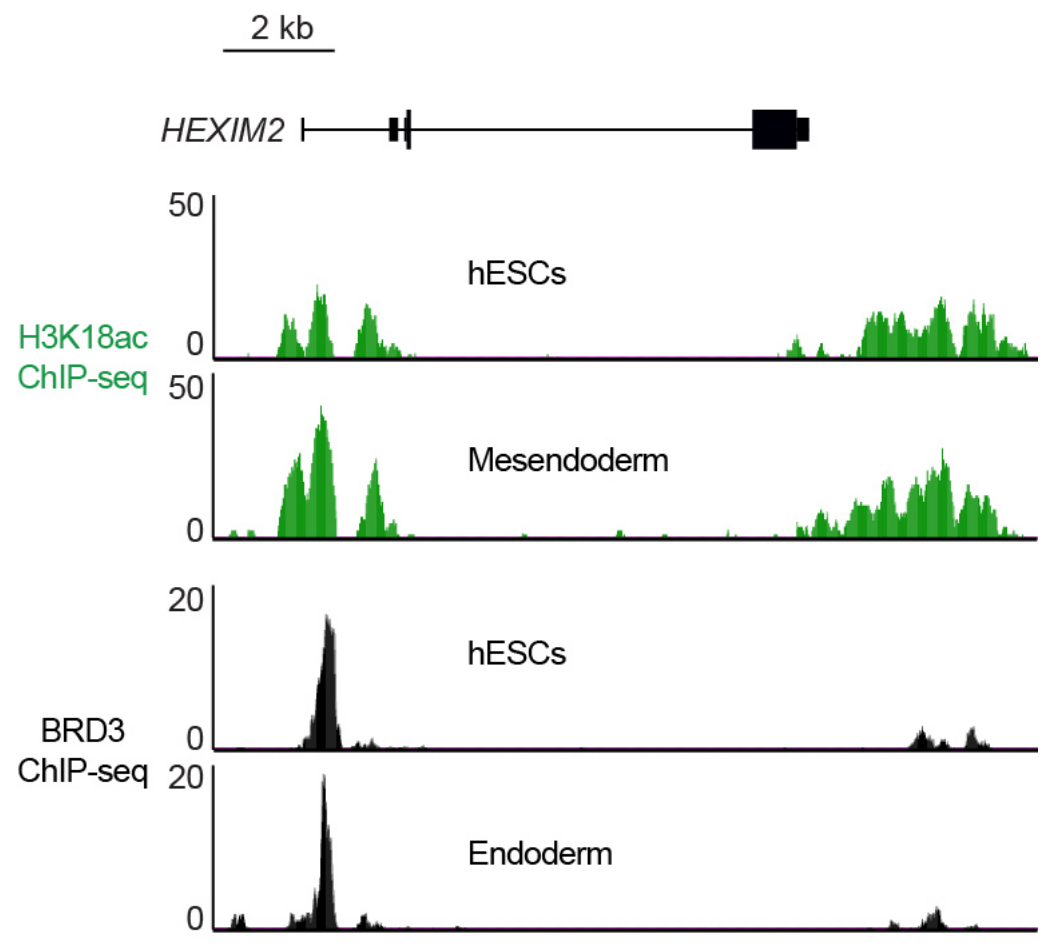

Figure S7. BRD3 occupies HEXIM2 locus in hESCs and endoderm.

ChIP-seq data shows H3K18ac (top, green) and BRD3 occupancy (bottom, black) at HEXIM2 in hESCs and endoderm / mesendoderm cells. 


\section{References}

Abmayr, S.M., Yao, T., Parmely, T., and Workman, J.L. (2006). Preparation of nuclear and cytoplasmic extracts from mammalian cells. Curr. Protoc. Mol. Biol. Chapter 12, Unit 12.1.

Alajem, A., Biran, A., Harikumar, A., Sailaja, B.S., Aaronson, Y., Livyatan, I., Nissim-Rafinia, M., Sommer, A.G., Mostoslavsky, G., Gerbasi, V.R., et al. (2015). Differential association of chromatin proteins identifies BAF60a/SMARCD1 as a regulator of embryonic stem cell differentiation. Cell Rep. 10, 2019-2031.

Anders, S., Pyl, P.T., and Huber, W. (2015). HTSeq--a Python framework to work with highthroughput sequencing data. Bioinformatics 31, 166-169.

Aranda, P.S., LaJoie, D.M., and Jorcyk, C.L. (2012). Bleach gel: a simple agarose gel for analyzing RNA quality. Electrophoresis 33, 366-369.

Banani, S.F., Lee, H.O., Hyman, A.A., and Rosen, M.K. (2017). Biomolecular condensates: organizers of cellular biochemistry. Nat. Rev. Mol. Cell Biol. 18, 285-298.

Basson, M.A. (2012). Signaling in cell differentiation and morphogenesis. Cold Spring Harb. Perspect. Biol. 4.

Bell, C.C., Amaral, P.P., Kalsbeek, A., Magor, G.W., Gillinder, K.R., Tangermann, P., di Lisio, L., Cheetham, S.W., Gruhl, F., Frith, J., et al. (2016). The Evx1/Evx1as gene locus regulates anterior-posterior patterning during gastrulation. Sci. Rep. 6, 26657.

Boija, A., Klein, I.A., Sabari, B.R., Dall'Agnese, A., Coffey, E.L., Zamudio, A.V., Li, C.H., Shrinivas, K., Manteiga, J.C., Hannett, N.M., et al. (2018). Transcription Factors Activate Genes through the Phase-Separation Capacity of Their Activation Domains. Cell 175, 1842-1855.e16.

Bose, D.A., Donahue, G., Reinberg, D., Shiekhattar, R., Bonasio, R., and Berger, S.L. (2017). RNA Binding to CBP Stimulates Histone Acetylation and Transcription. Cell 168, 135-149.e22.

Castello, A., Fischer, B., Frese, C.K., Horos, R., Alleaume, A.-M., Foehr, S., Curk, T., Krijgsveld, J., and Hentze, M.W. (2016). Comprehensive Identification of RNA-Binding Domains in Human Cells. Mol. Cell 63, 696-710.

Chicaybam, L., Sodre, A.L., Curzio, B.A., and Bonamino, M.H. (2013). An Efficient Low Cost Method for Gene Transfer to T Lymphocytes. PLoS One 8, e60298.

Creyghton, M.P., Cheng, A.W., Welstead, G.G., Kooistra, T., Carey, B.W., Steine, E.J., Hanna, J., Lodato, M.A., Frampton, G.M., Sharp, P.A., et al. (2010). Histone H3K27ac separates active from poised enhancers and predicts developmental state. Proc. Natl. Acad. Sci. U. S. A. 107, 21931-21936.

Cuatrecasas, P., Fuchs, S., and Anfinsen, C.B. (1967). Catalytic properties and specificity of the extracellular nuclease of Staphylococcus aureus. J. Biol. Chem. 242, 1541-1547.

D'Amour, K.A., Agulnick, A.D., Eliazer, S., Kelly, O.G., Kroon, E., and Baetge, E.E. (2005). Efficient differentiation of human embryonic stem cells to definitive endoderm. Nat. Biotechnol. 23, 1534-1541. 
Daneshvar, K., Pondick, J.V., Kim, B.-M., Zhou, C., York, S.R., Macklin, J.A., Abualteen, A., Tan, B., Sigova, A.A., Marcho, C., et al. (2016). DIGIT Is a Conserved Long Noncoding RNA that Regulates GSC Expression to Control Definitive Endoderm Differentiation of Embryonic Stem Cells. Cell Rep. 17, 353-365.

Deeney, J.T., Belkina, A.C., Shirihai, O.S., Corkey, B.E., and Denis, G.V. (2016). BET Bromodomain Proteins Brd2, Brd3 and Brd4 Selectively Regulate Metabolic Pathways in the Pancreatic $\beta$-Cell. PLoS One 11, e0151329.

Deglincerti, A., Etoc, F., Ozair, M.Z., and Brivanlou, A.H. (2016a). Self-Organization of Spatial Patterning in Human Embryonic Stem Cells. Curr. Top. Dev. Biol. 116, 99-113.

Deglincerti, A., Etoc, F., Guerra, M.C., Martyn, I., Metzger, J., Ruzo, A., Simunovic, M., Yoney, A., Brivanlou, A.H., Siggia, E., et al. (2016b). Self-organization of human embryonic stem cells on micropatterns. Nat. Protoc. 11, 2223-2232.

Delmore, J.E., Issa, G.C., Lemieux, M.E., Rahl, P.B., Shi, J., Jacobs, H.M., Kastritis, E., Gilpatrick, T., Paranal, R.M., Qi, J., et al. (2011). BET bromodomain inhibition as a therapeutic strategy to target c-Myc. Cell 146, 904-917.

Di Micco, R., Fontanals-Cirera, B., Low, V., Ntziachristos, P., Yuen, S.K., Lovell, C.D., Dolgalev, I., Yonekubo, Y., Zhang, G., Rusinova, E., et al. (2014). Control of embryonic stem cell identity by BRD4-dependent transcriptional elongation of super-enhancer-associated pluripotency genes. Cell Rep. 9, 234-247.

Dixon, J.R., Jung, I., Selvaraj, S., Shen, Y., Antosiewicz-Bourget, J.E., Lee, A.Y., Ye, Z., Kim, A., Rajagopal, N., Xie, W., et al. (2015). Chromatin architecture reorganization during stem cell differentiation. Nature 518, 331-336.

Engelen, E., Brandsma, J.H., Moen, M.J., Signorile, L., Dekkers, D.H.W., Demmers, J., Kockx, C.E.M., Ozgür, Z., van IJcken, W.F.J., van den Berg, D.L.C., et al. (2015). Proteins that bind regulatory regions identified by histone modification chromatin immunoprecipitations and mass spectrometry. Nat. Commun. 6, 7155.

Fernandez-Alonso, R., Davidson, L., Hukelmann, J., Zengerle, M., Prescott, A.R., Lamond, A., Ciulli, A., Sapkota, G.P., and Findlay, G.M. (2017). Brd4-Brd2 isoform switching coordinates pluripotent exit and Smad2-dependent lineage specification. EMBO Rep. 18, 1108-1122.

Filippakopoulos, P., Picaud, S., Mangos, M., Keates, T., Lambert, J.-P., Barsyte-Lovejoy, D., Felletar, I., Volkmer, R., Müller, S., Pawson, T., et al. (2012). Histone recognition and largescale structural analysis of the human bromodomain family. Cell 149, 214-231.

Flynn, R.A., and Chang, H.Y. (2014). Long noncoding RNAs in cell-fate programming and reprogramming. Cell Stem Cell 14, 752-761.

Garcia-Blanco, M.A., Jamison, S.F., and Sharp, P.A. (1989). Identification and purification of a 62,000-dalton protein that binds specifically to the polypyrimidine tract of introns. Genes Dev. 3, 1874-1886.

Gifford, C.A., Ziller, M.J., Gu, H., Trapnell, C., Donaghey, J., Tsankov, A., Shalek, A.K., Kelley, D.R., Shishkin, A.A., Issner, R., et al. (2013). Transcriptional and epigenetic dynamics during specification of human embryonic stem cells. Cell 153, 1149-1163. 
Grau, D.J., Chapman, B.A., Garlick, J.D., Borowsky, M., Francis, N.J., and Kingston, R.E. (2011). Compaction of chromatin by diverse Polycomb group proteins requires localized regions of high charge. Genes Dev. 25, 2210-2221.

He, C., Sidoli, S., Warneford-Thomson, R., Tatomer, D.C., Wilusz, J.E., Garcia, B.A., and Bonasio, R. (2016). High-Resolution Mapping of RNA-Binding Regions in the Nuclear Proteome of Embryonic Stem Cells. Mol. Cell 64, 416-430.

Houzelstein, D., Bullock, S.L., Lynch, D.E., Grigorieva, E.F., Wilson, V.A., and Beddington, R.S.P. (2002). Growth and early postimplantation defects in mice deficient for the bromodomain-containing protein Brd4. Mol. Cell. Biol. 22, 3794-3802.

Huang, D.W., Sherman, B.T., and Lempicki, R.A. (2009a). Systematic and integrative analysis of large gene lists using DAVID bioinformatics resources. Nat. Protoc. 4, 44-57.

Huang, D.W., Sherman, B.T., and Lempicki, R.A. (2009b). Bioinformatics enrichment tools: paths toward the comprehensive functional analysis of large gene lists. Nucleic Acids Res. 37, $1-13$.

Hutchinson, J.N., Ensminger, A.W., Clemson, C.M., Lynch, C.R., Lawrence, J.B., and Chess, A. (2007). A screen for nuclear transcripts identifies two linked noncoding RNAs associated with SC35 splicing domains. BMC Genomics 8, 39.

Ito, T., Ikehara, T., Nakagawa, T., Kraus, W.L., and Muramatsu, M. (2000). p300-mediated acetylation facilitates the transfer of histone $\mathrm{H} 2 \mathrm{~A}-\mathrm{H} 2 \mathrm{~B}$ dimers from nucleosomes to a histone chaperone. Genes Dev. 14, 1899-1907.

Jang, M.K., Mochizuki, K., Zhou, M., Jeong, H.-S., Brady, J.N., and Ozato, K. (2005). The Bromodomain Protein Brd4 Is a Positive Regulatory Component of P-TEFb and Stimulates RNA Polymerase II-Dependent Transcription. Mol. Cell 19, 523-534.

Janknecht, R., Wells, N.J., and Hunter, T. (1998). TGF-beta-stimulated cooperation of smad proteins with the coactivators CBP/p300. Genes Dev. 12, 2114-2119.

Jeon, Y., and Lee, J.T. (2011). YY1 tethers Xist RNA to the inactive X nucleation center. Cell $146,119-133$.

Jiang, W., Liu, Y., Liu, R., Zhang, K., and Zhang, Y. (2015). The IncRNA DEANR1 facilitates human endoderm differentiation by activating FOXA2 expression. Cell Rep. 11, 137-148.

Jin, Q., Yu, L.-R., Wang, L., Zhang, Z., Kasper, L.H., Lee, J.-E., Wang, C., Brindle, P.K., Dent, S.Y.R., and Ge, K. (2011). Distinct roles of GCN5/PCAF-mediated H3K9ac and CBP/p300mediated H3K18/27ac in nuclear receptor transactivation. EMBO J. 30, 249-262.

Kanno, T., Kanno, Y., Siegel, R.M., Jang, M.K., Lenardo, M.J., and Ozato, K. (2004). Selective recognition of acetylated histones by bromodomain proteins visualized in living cells. Mol. Cell 13, 33-43.

Kent, W.J., Zweig, A.S., Barber, G., Hinrichs, A.S., and Karolchik, D. (2010). BigWig and BigBed: enabling browsing of large distributed datasets. Bioinformatics 26, 2204-2207.

Kowarz, E., Löscher, D., and Marschalek, R. (2015). Optimized Sleeping Beauty transposons rapidly generate stable transgenic cell lines. Biotechnol. J. 10, 647-653. 
Kubo, A., Shinozaki, K., Shannon, J.M., Kouskoff, V., Kennedy, M., Woo, S., Fehling, H.J., and Keller, G. (2004). Development of definitive endoderm from embryonic stem cells in culture. Development 131, 1651-1662.

Langmead, B., and Salzberg, S.L. (2012). Fast gapped-read alignment with Bowtie 2. Nat. Methods 9, 357-359.

Leppek, K., and Stoecklin, G. (2014). An optimized streptavidin-binding RNA aptamer for purification of ribonucleoprotein complexes identifies novel ARE-binding proteins. Nucleic Acids Res. 42, e13.

LeRoy, G., Rickards, B., and Flint, S.J. (2008). The double bromodomain proteins Brd2 and Brd3 couple histone acetylation to transcription. Mol. Cell 30, 51-60.

Li, H., Handsaker, B., Wysoker, A., Fennell, T., Ruan, J., Homer, N., Marth, G., Abecasis, G., Durbin, R., and 1000 Genome Project Data Processing Subgroup (2009). The Sequence Alignment/Map format and SAMtools. Bioinformatics 25, 2078-2079.

Lin, N., Chang, K.-Y., Li, Z., Gates, K., Rana, Z.A., Dang, J., Zhang, D., Han, T., Yang, C.-S., Cunningham, T.J., et al. (2014). An evolutionarily conserved long noncoding RNA TUNA controls pluripotency and neural lineage commitment. Mol. Cell 53, 1005-1019.

Liu, L., Xu, Y., He, M., Zhang, M., Cui, F., Lu, L., Yao, M., Tian, W., Benda, C., Zhuang, Q., et al. (2014). Transcriptional pause release is a rate-limiting step for somatic cell reprogramming. Cell Stem Cell 15, 574-588.

Lu, H., Yu, D., Hansen, A.S., Ganguly, S., Liu, R., Heckert, A., Darzacq, X., and Zhou, Q. (2018). Phase-separation mechanism for C-terminal hyperphosphorylation of RNA polymerase II. Nature 558, 318-323.

Luo, S., Lu, J.Y., Liu, L., Yin, Y., Chen, C., Han, X., Wu, B., Xu, R., Liu, W., Yan, P., et al. (2016). Divergent IncRNAs Regulate Gene Expression and Lineage Differentiation in Pluripotent Cells. Cell Stem Cell 18, 637-652.

Mellacheruvu, D., Wright, Z., Couzens, A.L., Lambert, J.-P., St-Denis, N.A., Li, T., Miteva, Y.V., Hauri, S., Sardiu, M.E., Low, T.Y., et al. (2013). The CRAPome: a contaminant repository for affinity purification-mass spectrometry data. Nat. Methods 10, 730-736.

Oh, J., Sohn, D.H., Ko, M., Chung, H., Jeon, S.H., and Seong, R.H. (2008). BAF60a interacts with p53 to recruit the SWI/SNF complex. J. Biol. Chem. 283, 11924-11934.

Paillisson, A., Levasseur, A., Gouret, P., Callebaut, I., Bontoux, M., Pontarotti, P., and Monget, P. (2007). Bromodomain testis-specific protein is expressed in mouse oocyte and evolves faster than its ubiquitously expressed paralogs BRD2, -3, and -4. Genomics 89, 215-223.

Postepska-lgielska, A., Giwojna, A., Gasri-Plotnitsky, L., Schmitt, N., Dold, A., Ginsberg, D., and Grummt, I. (2015). LncRNA Khps1 Regulates Expression of the Proto-oncogene SPHK1 via Triplex-Mediated Changes in Chromatin Structure. Mol. Cell 60, 626-636.

Pouponnot, C., Jayaraman, L., and Massagué, J. (1998). Physical and functional interaction of SMADs and p300/CBP. J. Biol. Chem. 273, 22865-22868.

Putnam, F.W., and Neurath, H. (1944). The Precipitation of Proteins by Synthetic Detergents 
1a. J. Am. Chem. Soc. 66, 692-697.

Rada-Iglesias, A., Bajpai, R., Swigut, T., Brugmann, S.A., Flynn, R.A., and Wysocka, J. (2011). A unique chromatin signature uncovers early developmental enhancers in humans. Nature 470, 279-283.

Rahnamoun, H., Lee, J., Sun, Z., Lu, H., Ramsey, K.M., Komives, E.A., and Lauberth, S.M. (2018). RNAs interact with BRD4 to promote enhanced chromatin engagement and transcription activation. Nat. Struct. Mol. Biol. 25, 687-697.

Ramírez, F., Ryan, D.P., Grüning, B., Bhardwaj, V., Kilpert, F., Richter, A.S., Heyne, S., Dündar, F., and Manke, T. (2016). deepTools2: a next generation web server for deep-sequencing data analysis. Nucleic Acids Res. 44, W160-W165.

Ramos, A.D., Andersen, R.E., Liu, S.J., Nowakowski, T.J., Hong, S.J., Gertz, C.C., Salinas, R.D., Zarabi, H., Kriegstein, A.R., and Lim, D.A. (2015). The Long Noncoding RNA Pnky Regulates Neuronal Differentiation of Embryonic and Postnatal Neural Stem Cells. Cell Stem Cell 16, 439-447.

Rinn, J.L., Kertesz, M., Wang, J.K., Squazzo, S.L., Xu, X., Brugmann, S.A., Goodnough, L.H., Helms, J.A., Farnham, P.J., Segal, E., et al. (2007). Functional demarcation of active and silent chromatin domains in human HOX loci by noncoding RNAs. Cell 129, 1311-1323.

Sabari, B.R., Dall'Agnese, A., Boija, A., Klein, I.A., Coffey, E.L., Shrinivas, K., Abraham, B.J., Hannett, N.M., Zamudio, A.V., Manteiga, J.C., et al. (2018). Coactivator condensation at superenhancers links phase separation and gene control. Science 361.

Saltzman, A.L., Soo, M.W., Aram, R., and Lee, J.T. (2018). Multiple Histone Methyl-Lysine Readers Ensure Robust Development and Germline Immortality in. Genetics.

Shang, E., Wang, X., Wen, D., Greenberg, D.A., and Wolgemuth, D.J. (2009). Double bromodomain-containing gene Brd2 is essential for embryonic development in mouse. Dev. Dyn. 238, 908-917.

Sigova, A.A., Mullen, A.C., Molinie, B., Gupta, S., Orlando, D.A., Guenther, M.G., Almada, A.E., Lin, C., Sharp, P.A., Giallourakis, C.C., et al. (2013). Divergent transcription of long noncoding RNA/mRNA gene pairs in embryonic stem cells. Proc. Natl. Acad. Sci. U. S. A. 110, 2876-2881.

Skene, P.J., and Henikoff, S. (2017). An efficient targeted nuclease strategy for high-resolution mapping of DNA binding sites. Elife 6.

Skene, P.J., Henikoff, J.G., and Henikoff, S. (2018). Targeted in situ genome-wide profiling with high efficiency for low cell numbers. Nat. Protoc. 13, 1006-1019.

Srisawat, C., and Engelke, D.R. (2001). Streptavidin aptamers: affinity tags for the study of RNAs and ribonucleoproteins. RNA 7, 632-641.

Tada, S., Era, T., Furusawa, C., Sakurai, H., Nishikawa, S., Kinoshita, M., Nakao, K., Chiba, T., and Nishikawa, S.-I. (2005). Characterization of mesendoderm: a diverging point of the definitive endoderm and mesoderm in embryonic stem cell differentiation culture. Development 132, 4363-4374.

Vallier, L., Touboul, T., Chng, Z., Brimpari, M., Hannan, N., Millan, E., Smithers, L.E., Trotter, 
M., Rugg-Gunn, P., Weber, A., et al. (2009). Early cell fate decisions of human embryonic stem cells and mouse epiblast stem cells are controlled by the same signalling pathways. PLoS One 4, e6082.

Wai, D.C.C., Szyszka, T.N., Campbell, A.E., Kwong, C., Wilkinson-White, L.E., Silva, A.P.G., Low, J.K.K., Kwan, A.H., Gamsjaeger, R., Chalmers, J.D., et al. (2018). The BRD3 ET domain recognizes a short peptide motif through a mechanism that is conserved across chromatin remodelers and transcriptional regulators. J. Biol. Chem. 293, 7160-7175.

Warmflash, A., Sorre, B., Etoc, F., Siggia, E.D., and Brivanlou, A.H. (2014). A method to recapitulate early embryonic spatial patterning in human embryonic stem cells. Nat. Methods 11, 847-854.

West, J.A., Davis, C.P., Sunwoo, H., Simon, M.D., Sadreyev, R.I., Wang, P.I., Tolstorukov, M.Y., and Kingston, R.E. (2014). The Long Noncoding RNAs NEAT1 and MALAT1 Bind Active Chromatin Sites. Mol. Cell 55, 791-802.

Xi, Q., Wang, Z., Zaromytidou, A.-I., Zhang, X.H.-F., Chow-Tsang, L.-F., Liu, J.X., Kim, H., Barlas, A., Manova-Todorova, K., Kaartinen, V., et al. (2011). A poised chromatin platform for TGF- $\beta$ access to master regulators. Cell 147, 1511-1524.

Yamazaki, T., Souquere, S., Chujo, T., Kobelke, S., Chong, Y.S., Fox, A.H., Bond, C.S., Nakagawa, S., Pierron, G., and Hirose, T. (2018). Functional Domains of NEAT1 Architectural IncRNA Induce Paraspeckle Assembly through Phase Separation. Mol. Cell 70, 1038-1053.e7.

Yap, K.L., Li, S., Muñoz-Cabello, A.M., Raguz, S., Zeng, L., Mujtaba, S., Gil, J., Walsh, M.J., and Zhou, M.-M. (2010). Molecular interplay of the noncoding RNA ANRIL and methylated histone $\mathrm{H} 3$ lysine 27 by polycomb CBX7 in transcriptional silencing of INK4a. Mol. Cell 38, 662674.

Zhang, Y., Liu, T., Meyer, C.A., Eeckhoute, J., Johnson, D.S., Bernstein, B.E., Nusbaum, C., Myers, R.M., Brown, M., Li, W., et al. (2008). Model-based analysis of ChIP-Seq (MACS). Genome Biol. 9, R137.

Zuber, J., Shi, J., Wang, E., Rappaport, A.R., Herrmann, H., Sison, E.A., Magoon, D., Qi, J., Blatt, K., Wunderlich, M., et al. (2011). RNAi screen identifies Brd4 as a therapeutic target in acute myeloid leukaemia. Nature 478, 524-528. 